\title{
Pulmonary Hypertension in an Oncologic Intensive Care Unit
}

\author{
Lilit A. Sargsyan and Saadia A. Faiz
}

\section{Contents}

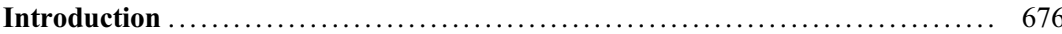

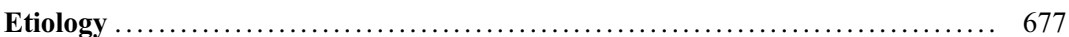

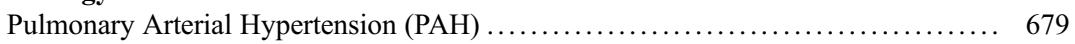

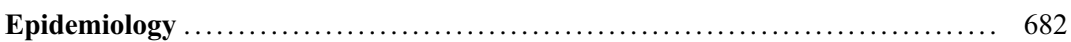

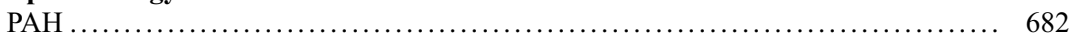

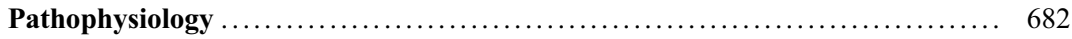

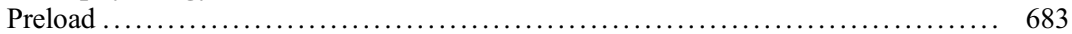

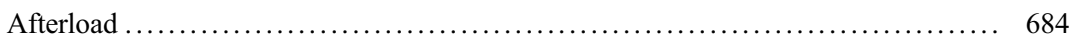

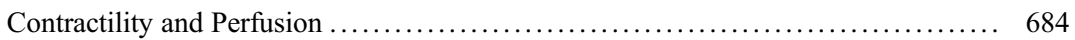

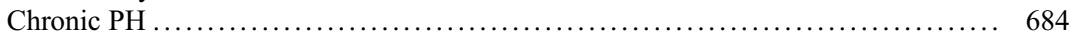

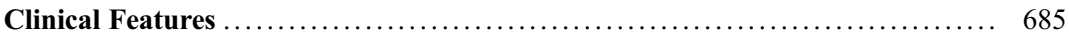

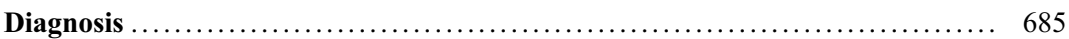

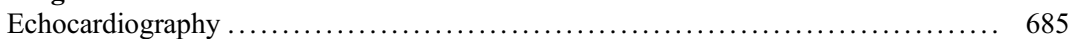

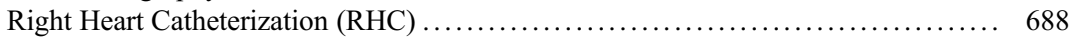

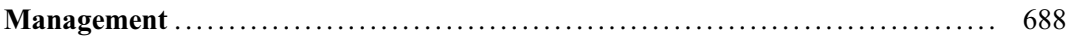

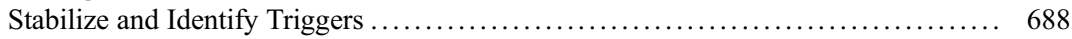

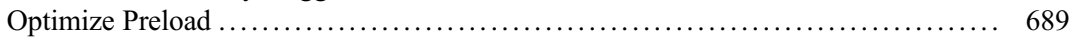

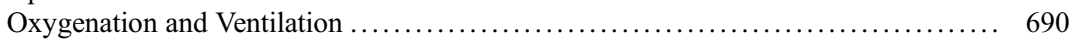

Reduce Right Ventricular (RV) Afterload ............................. 690

L. A. Sargsyan

Divisions of Critical Care, Pulmonary, and Sleep

Medicine, Department of Internal Medicine, McGovern

Medical School at The University of Texas Health Science

Center at Houston, Houston, TX, USA

e-mail: lilit.a.sargsyan@uth.tmc.edu

\section{S. A. Faiz $(\bowtie)$}

Department of Pulmonary Medicine, Division of Internal Medicine, The University of Texas MD Anderson Cancer

Center, Houston, TX, USA

e-mail: safaiz@mdanderson.org 


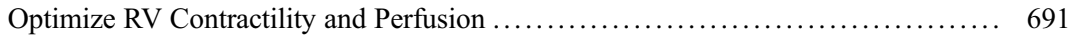

Pharmacologic Treatment Modalities .................................... 692

Nonpharmacologic Treatment Modalities ................................... 692

End-of-Life Care ............................................. 694

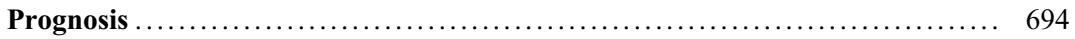

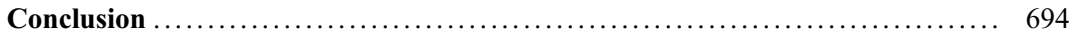

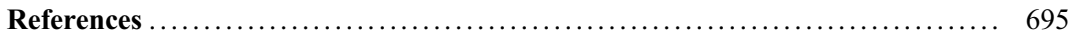

\section{Abstract}

Pulmonary hypertension $(\mathrm{PH})$ is the condition of elevated pressures in the pulmonary circulation. PH can develop acutely in patients with critical illness such as acute respiratory distress syndrome, sepsis, massive pulmonary embolism, left ventricular dysfunction, or after surgery. In a cancer patient, unique etiologies such as myeloproliferative disorders, tyrosine kinase inhibitors, or tumor emboli may result in PH. Early recognition and treatment of the causative condition may reverse acute $\mathrm{PH}$ or return chronic $\mathrm{PH}$ to its baseline status. Progression of the disease or its decompensation due to infection, a thromboembolic event, or other triggers can lead to admission to an intensive care unit. Regardless of etiology, the development or worsening of $\mathrm{PH}$ may precipitate hypoxemia, hemodynamic instability, or right ventricular failure, which can be challenging to manage or even fatal. In select cases, rapid institution of advanced treatment modalities may be warranted. This chapter reviews the etiology, epidemiology, pathophysiology, clinical features, diagnosis, and prognosis of $\mathrm{PH}$ and presents a comprehensive analysis of $\mathrm{PH}$ and right heart failure management strategies in the critical care setting. In particular, a unique perspective on oncologically relevant $\mathrm{PH}$ is provided.

\section{Keywords}

Pulmonary hypertension - Intensive care · Critical care $\cdot$ Cancer $\cdot$ Myeloproliferative disorders $\cdot$ Pulmonary embolism $\cdot$ Cor pulmonale $\cdot \mathrm{PAH} \cdot \mathrm{TKI} \cdot \mathrm{RV}$ failure

\section{Introduction}

Pulmonary hypertension (PH) represents a complex and challenging dimension in the management of critically ill patients. Historically, the left heart was considered to be the only pump and the dominant force in the cardiovascular system, while the right heart was seen as a passive conduit through which blood flowed for reoxygenation. The function and importance of the right ventricle (RV) is now much better understood, largely due to the growing experience with right ventricular failure (RVF). Moreover, recent studies have identified RV function as a major determinant of outcomes including mortality, especially after myocardial infarction, in acute pulmonary embolism, and in moderate left heart failure [26]. In the intensive care unit (ICU), acute RV dysfunction has been well described with septic shock and acute respiratory distress syndrome (ARDS), and a decompensated RV, especially in those with chronic PH, portends limited survival [13]. Thus, early detection and treatment of $\mathrm{PH}$ and impending RVF can significantly improve outcomes. The RV differs from the left ventricle in both structure and function, and management of a failing RV is fundamentally different. Distinct etiologies for $\mathrm{PH}$ exist in the oncologic patient. The purpose of this chapter is to review the etiologies, epidemiology, and clinical features of $\mathrm{PH}$ in the oncologic patient, followed by a broad discussion of the pathophysiology, diagnosis, management strategies, and prognosis for subsequent RVF in the critical care setting. 


\section{Etiology}

$\mathrm{PH}$ in the ICU may be associated with a number of causative factors (Table 1), with the most common being left heart failure, sepsis, acute respiratory insufficiency with hypoxia, pulmonary embolism, ARDS, or decompensation of chronic $\mathrm{PH}$. $\mathrm{PH}$ is defined as mean pulmonary artery pressure greater than or equal to $25 \mathrm{~mm} \mathrm{Hg}$. The World Health Organization (WHO) classifies $\mathrm{PH}$ into groups based on etiology, hemodynamics, and treatment options. This classification has evolved from two to five categories as follows: group 1, pulmonary arterial hypertension (PAH); group 2, $\mathrm{PH}$ due to left heart disease; group 3, $\mathrm{PH}$ due to hypoxia or lung disease; group 4, chronic thromboembolic pulmonary hypertension (CTEPH); and group 5, PH caused by multifactorial mechanisms [80].

The most common cause of right heart failure is left heart failure. In fact, $\mathrm{PH}$ secondary to left heart disease (WHO group 2) was recently shown to comprise $69 \%$ of all $\mathrm{PH}$, of which $49 \%$ was due to valvular disease, $31 \%$ to left ventricular systolic dysfunction, and $21 \%$ to left ventricular diastolic dysfunction [90]. In addition, $\mathrm{PH}$ was found in up to $60 \%$ of patients with severe systolic heart failure, up to $70 \%$ in those with heart failure with preserved ejection fraction, up to $65 \%$ in those with symptomatic aortic stenosis, and in practically everyone with severe symptomatic mitral valve disease [47, 65]. WHO group $2 \mathrm{PH}$ is associated with mean left atrial pressures of $>14 \mathrm{mmHg}$ which can result in pulmonary venous hypertension, also known as post-capillary $\mathrm{PH}$. Conditions in this category include left ventricular systolic and diastolic dysfunction, constrictive pericarditis, left atrial myxoma, valvular disease, congenital or acquired left heart inflow/outflow tract obstruction, and congenital cardiomyopathies. Chemotherapyinduced cardiotoxicity may occur in patients having received anthracycline-based regimens, tyrosine kinase inhibitors, alkylating agents, or taxanes [79]. Radiation fields that involve the heart may also accelerate coronary atherosclerosis and induce acute or chronic pericardial disease, valvular heart disease, conduction system disease, and cardiomyopathy [92]. Young age and left anterior thoracic radiation place patients at higher risk for cardiac damage [31]. Infiltrative diseases such as amyloidosis may also manifest with restrictive cardiomyopathy or $\mathrm{PH}$.

Patients in WHO group 3 have $\mathrm{PH}$ due to lung disease and/or hypoxia, including chronic obstructive pulmonary disease (COPD), interstitial lung disease (ILD), other lung diseases with mixed restrictive and obstructive patterns, sleepdisordered breathing such as obstructive sleep apnea, alveolar hypoventilation disorders such as obesity hypoventilation syndrome, and neuromuscular weakness. ARDS promotes hypoxic vasoconstriction, increases alveolar dead space, and releases pro-inflammatory cytokines and pulmonary microthrombi, all of which may result in RVF in up to $30-56 \%$ of cases [28]. Predictors of RVF in ARDS include pneumonia-induced ARDS, partial pressure of arterial oxygen/fraction of inspired oxygen ratio $<150$, partial pressure of carbon dioxide $>47 \mathrm{mmHg}$, and a driving pressure (end-inspiratory plateau pressure minus the positive end-expiratory pressure, PEEP) $>18 \mathrm{~cm}$ $\mathrm{H}_{2} \mathrm{O}$ [61]. Pneumonitis from infections, aspiration, radiation therapy, or drugs can also cause hypoxic pulmonary vasoconstriction resulting in PH. A myriad of chemotherapeutic agents including anti-epidermal growth factor receptor, smallmolecule tyrosine kinase inhibitors, mTOR inhibitors, anti-lymphocyte monoclonal antibodies, and even immunotherapy may result in lung injury $[3,71]$. Degree of hypoxemic respiratory insufficiency may be compounded if new infiltrates are superimposed on underlying COPD, ILD, or metastatic or primary lung cancer.

Cancer is a well-known cause of venous thromboembolism, and pulmonary embolism may certainly present with $\mathrm{PH}$ and, potentially, hemodynamic instability. In a large populationbased, case-controlled study to identify risk factors for venous thrombosis, a sevenfold increase in patients with malignancy compared to patients without malignancy was found [7]. Interestingly, there was a 28 -fold increase in those with hematologic malignancies, followed by lung cancer and gastrointestinal cancer. Certain anti- 
Table 1 Etiologies of pulmonary hypertension $(\mathrm{PH})$ and precipitants of acute right heart failure

\begin{tabular}{|c|c|c|}
\hline & General PH & Oncologic-related $\mathrm{PH}$ \\
\hline Cardiac & $\begin{array}{l}\text { - Acute LV failure (systolic, diastolic) } \\
\text { - LV ischemia or infarction } \\
\text { - RV ischemia or infarction } \\
\text { - Arrhythmias (SVT or VT) } \\
\text { - Congenital heart disease (e.g., ASD, } \\
\text { VSD, Ebstein's anomaly) } \\
\text { - Valvulopathies (TR, pulmonary valve } \\
\text { stenosis) } \\
\text { - Cardiomyopathies including infiltrative } \\
\text { disorders } \\
\text { - Myocarditis or other inflammatory } \\
\text { disorders } \\
\text { - Pericardial disease (tamponade, } \\
\text { constrictive pericarditis) }\end{array}$ & $\begin{array}{l}\text { - Amyloidosis } \\
\text { - Carcinoid heart disease } \\
\text { - Cardiac tumors } \\
\text { - Radiation therapy } \\
\text { - SVC syndrome } \\
\text { - Anthracyclines (doxorubicin, epirubicin, idarubicin) } \\
\text { - Anthraquinone (mitoxantrone) } \\
\text { - Alkylating agents (cyclophosphamide, ifosfamide) } \\
\text { - Taxanes (docetaxel) } \\
\text { - Tyrosine kinase inhibitors (monoclonal antibody, } \\
\text { trastuzumab, bevacizumab; small molecules, sunitinib, } \\
\text { dasatinib, imatinib, lapatinib; antimetabolites, } \\
\text { clofarabine; proteasome inhibitor, bortezomib) }\end{array}$ \\
\hline Endocrine & $\begin{array}{l}\text { - Thyrotoxicosis } \\
\text { - Pregnancy }\end{array}$ & $\begin{array}{l}\text { - Thyroid cancer } \\
\text { - Immunotherapy }\end{array}$ \\
\hline Hematologic & $\begin{array}{l}\text { - Acute chest syndrome in sickle cell } \\
\text { disease } \\
\text { - Beriberi syndrome } \\
\text { - Anemia }\end{array}$ & $\begin{array}{l}\text { - Chronic myeloproliferative disorders (PAH, CTEPH) } \\
\text { - Multiple myeloma }\end{array}$ \\
\hline Infection & - Systemic inflammatory states and sepsis & - Cancer patients susceptible due to immunosuppression \\
\hline Surgery & $\begin{array}{l}\text { - Cardiac surgery (e.g., cardiac transplant } \\
\text { or LVAD implantation, CAB, valvular) } \\
\text { - Noncardiac surgery (e.g., abdominal, } \\
\text { vascular) }\end{array}$ & $\begin{array}{l}\text { - Surgery involving tumors around and in the pulmonary } \\
\text { circulation and lung resection }\end{array}$ \\
\hline Pulmonary & $\begin{array}{l}\text { - ARDS } \\
\text { - Acute pulmonary embolism } \\
\text { - Hypoxic pulmonary vasoconstriction } \\
\text { related to parenchymal lung injury } \\
\text { (pneumonia) } \\
\text { - Mechanical ventilation } \\
\text { - Exacerbation of lung disease (COPD, } \\
\text { ILD, bronchiectasis) } \\
\text { - Withdrawal of chronic PH therapy } \\
\text { - PH (WHO groups 1-5) } \\
\text { - Group 1, pulmonary arterial } \\
\text { hypertension (PAH) } \\
\text { - Group 1, PVOD and/or PCH } \\
\text { - Group 2, PH due to left heart disease } \\
\text { - Group 3, PH due to lung disease } \\
\text { and/or hypoxia including } \\
\text { OSA/OHS } \\
\text { - Group 4, chronic thromboembolic } \\
\text { pulmonary hypertension (CTEPH) } \\
\text { - Group 5, pulmonary hypertension } \\
\text { with unclear multifactorial } \\
\text { mechanisms }\end{array}$ & $\begin{array}{l}\text { - Pneumonitis from drugs } \\
\text { - Radiation injury (acute and chronic) } \\
\text { - Pulmonary emboli } \\
\text { - PAH (tyrosine kinase inhibitors, chronic } \\
\text { myeloproliferative disease) } \\
\text { - CTEPH } \\
\text { - Pulmonary circulation tumors (pulmonary artery } \\
\text { sarcoma, pulmonary vein sarcoma) } \\
\text { - Fibrosing mediastinitis (radiation, fungal infection) } \\
\text { - Tumor emboli (adenocarcinoma) } \\
\text { - PVOD }\end{array}$ \\
\hline
\end{tabular}

Definition of abbreviations: LV, left ventricular; RV, right ventricular; SVT, supraventricular tachycardia; VT, ventricular tachycardia; ASD, atrial septal defect; VSD, ventricular septal defect; TR, tricuspid regurgitation; SVC, superior vena cava; LVAD, left ventricular assist device; CAB, coronary artery bypass; ARDS, acute respiratory distress syndrome; COPD, chronic obstructive pulmonary disease; ILD, interstitial lung disease; WHO, World Health Organization; PAH, pulmonary arterial hypertension; PVOD, pulmonary veno-occlusive disease; $\mathrm{PCH}$, pulmonary capillary hemangiomatosis; OSA, obstructive sleep apnea; OHS, obesity hypoventilation syndrome; CTEPH, chronic thromboembolic pulmonary hypertension 
angiogenic agents such as thalidomide and vascular endothelial growth factor inhibitors such as bevacizumab may increase the incidence of pulmonary emboli during therapy. Cancer patients often have incidental pulmonary emboli on routine imaging. CTEPH has been described in patients with chronic myeloproliferative disease, subsequently treated with pulmonary vasodilator therapy or thromboendarterectomy [30]. The incidence of CTEPH in cancer populations has not been established, likely due to limitation in longterm follow-up.

$\mathrm{PH}$ due to mixed or unclear mechanisms in miscellaneous malignant and nonmalignant conditions is classified under WHO group 5. Such conditions include hematologic disorders (chronic hemolytic anemia, myeloproliferative disorders, splenectomy), systemic disorders (sarcoidosis, pulmonary histiocytosis, lymphangioleiomyomatosis), metabolic disorders (glycogen storage diseases, Gaucher disease, thyroid disorders), as well as tumoral obstruction, fibrosing mediastinitis, chronic renal failure, and segmental $\mathrm{PH}$. Chronic myeloproliferative disorders comprise a rare cause of $\mathrm{PH}$. The potential mechanisms include splenectomy, direct obstruction of pulmonary arteries, chronic thromboembolism, portal hypertension, high cardiac output, and left heart failure [80]. Attributing PH solely to chronic myeloproliferative disease is difficult, as many of the reported cases did not have a right heart catheterization (RHC) needed to definitively diagnose PAH and rule out other causes such as left heart disease [54]. Multiple myeloma has also been associated with $\mathrm{PH}$ with potential etiologies that include concomitant amyloidosis, left heart dysfunction, chronic kidney failure, and treatment-related toxicities [50]. Other etiologies of PH in group 5 may be from obstruction of pulmonary vasculature from metastatic disease or primary tumors of the pulmonary vasculature (e.g., pulmonary artery sarcoma), or fibrosing mediastinitis due to previous radiation therapy or fungal infection such as histoplasmosis. Finally, an autopsy series has estimated that 6 to $26 \%$ of patients with solid tumors, primarily adenocarcinoma, have pulmonary tumor emboli [74], and these patients may sometimes present antemortem with acute or subacute cor pulmonale [23].

\section{Pulmonary Arterial Hypertension (PAH)}

PAH is a disease state that directly affects the pulmonary vasculature and includes idiopathic and heritable $\mathrm{PAH}, \mathrm{PAH}$ caused by drugs or toxins, PAH associated with connective tissue disease, human immunodeficiency virus (HIV) infection, portal hypertension, congenital heart disease, schistosomiasis, pulmonary venoocclusive disease (PVOD), and pulmonary capillary hemangiomatosis $(\mathrm{PCH})$. In order to be recognized as WHO group 1, specific criteria for PAH based on RHC must be met (Table 2). PAH has a progressive clinical course studded with episodes of acute decompensation, eventually leading to severe symptoms and heart failure. Death from PAH may occur suddenly in an outof-hospital setting or slowly from inexorable right heart failure, often necessitating a hospitalization and, frequently, an ICU admission. Even mild, typically reversible events (e.g., infection, new anemia, a small pulmonary embolism) can trigger clinical deterioration.

Sepsis is the most common reason for a patient with PAH to be admitted to the ICU [83], and it should be diagnosed and treated according to the Surviving Sepsis Campaign International guidelines [72]. Special care should be taken to closely monitor hemodynamic status and administer crystalloids cautiously as part of the initial resuscitation in order to prevent volume overload. Pericardial effusion in PAH typically occurs in 13 to $44 \%$ of cases, but this number rises with conditions that independently carry a higher incidence of pericardial effusion, such as cancer or collagen vascular disease. Given the chronically elevated right-sided pressures, cardiac tamponade manifests atypically with left atrial and ventricular diastolic collapse [75]. Pulsus paradoxus is also often absent due to the inability of the stiff and dilated RV to pull in more volume during inspiration [19].

There are a few cancer-related etiologies for PAH. Dasatinib, a tyrosine kinase inhibitor used to treat acute and chronic leukemia, has been reported to cause $\mathrm{PAH}$, and in most cases cessation of the drug resolves the PAH [62]. The new generation of tyrosine kinase inhibitors 
Table 2 Diagnostic testing for pulmonary hypertension and right ventricular failure

\begin{tabular}{|c|c|}
\hline \multicolumn{2}{|l|}{ Cardiac } \\
\hline Electrocardiographic signs & $\begin{array}{l}\text { - Right axis deviation, right bundle branch block, anteroseptal ST and T wave } \\
\text { changes, P pulmonale (right atrial enlargement), RV hypertrophy, QTc } \\
\text { prolongation, and RV strain } \\
\text { - Signs of possible PE: sinus tachycardia, "S1Q3T3" }\end{array}$ \\
\hline Echocardiographic signs & $\begin{array}{l}\text { - Pulmonary artery systolic pressure }>40 \mathrm{mmHg} \text { is suggestive of PH } \\
\text { - Depends on peak TR jet }+ \text { estimated right atrial pressure [45] } \\
\text { - Underestimated when TR jet is minimal } \\
\text { - Overestimated in significant anemia } \\
\text { - RV size and function } \\
\text { - RVEF }<45 \%, \mathrm{RV} \text { enlargement and hypertrophy } \\
\text { - TAPSE }<18 \mathrm{~mm} \text { (normal } 2.4-2.7 \mathrm{~cm} \text { ) } \\
\text { - RV/LV basal diameter ratio }>1.0 \\
\text { - IVS flat ("D sign") or bowed into LV (in systole } \rightarrow \mathrm{RV} \text { pressure overload, in } \\
\text { diastole } \rightarrow \text { RV volume overload) } \\
\text { - McConnell sign: early and specific sign of an acute PE } \\
\text { - Regional pattern of RV dysfunction with akinesia of the mid-free wall and a } \\
\quad \text { normal RV apex [ } 57] \\
\text { - Severity of TR: peak TR velocity } \geq 3 \mathrm{~m} / \mathrm{s} \text { is suggestive of PH } \\
\text { - Pericardial fluid: poor prognostic sign in PAH } \\
\text { - Clues for causes of PH } \\
\text { - Left heart disease: depressed LVEF, diastolic dysfunction, valvular disease, } \\
\text { infiltrative cardiomyopathies } \\
\text { - Interatrial shunts seen with an agitated saline bubble study } \\
\text { - Signs of volume overload } \\
\text { - Inferior vena cava diameter }>21 \mathrm{~mm} \text { with decreased respiratory collapse } \\
\text { - Right end-systolic atrial area }>18 \mathrm{~cm}{ }^{2} \text { [23] } \\
\text { - Systolic flow reversal in hepatic veins from severe TR, RV overload, RV stiffness }\end{array}$ \\
\hline Right heart catheterization & $\begin{array}{l}\text { - Normal: mean pulmonary artery pressures are considered to be around } \\
14 \pm 3 \mathrm{mmHg} \text { with upper limit of normal of } 20 \mathrm{mmHg}[37] \\
\text { - At risk for PH: mean PAPs of } 21-24 \mathrm{mmHg} \\
\text { - PAH: mean pulmonary artery pressure } \geq 25 \mathrm{mmHg} \text {, pulmonary capillary wedge } \\
\text { pressure (PCWP) } \leq 15 \mathrm{mmHg} \text {, pulmonary vascular resistance (PVR) }>3 \text { wood } \\
\text { units [23] } \\
\text { - Markers of poor survival: } \mathrm{CI}<2.2 \mathrm{~L} / \mathrm{min} / \mathrm{m}^{2} \text {, elevated RAP [4] } \\
\text { - Pre-capillary PH: PAH, PH due to lung disease, chronic thromboembolic PH } \\
\text { (CTEPH), PH with unclear etiology or with multifactorial etiologies, } \\
\text { end-expiratory PCWP of } \leq 15 \mathrm{mmHg}[37] \\
\text { - Post-capillary PH: PH from left heart disease, PH of unclear etiology and/or } \\
\text { multifactorial mechanisms, PCWP }>15 \mathrm{mmHg} \\
\text { - DPG (diastolic PAP minus mean PCWP) and the pulmonary vascular resistance } \\
\text { (PVR) can help distinguish between isolated post-capillary and combined pre- and } \\
\text { post-capillary PH [23] } \\
\text { - DPG }<7 \mathrm{mmHg} \text { and PVR }<3 \mathrm{WU}=\text { isolated post-capillary PH } \\
\text { - DPG of } \geq 7 \mathrm{mmHg} \text { or PVR } \geq 3 \mathrm{WU}=\text { both pre- and post-capillary PH }\end{array}$ \\
\hline \multicolumn{2}{|l|}{ Imaging } \\
\hline Chest radiography & $\begin{array}{l}\text { - Enlarged cardiac silhouette, decreased retrosternal air space on lateral film } \\
\text { (RV enlargement), enlarged central pulmonary arteries }\end{array}$ \\
\hline Computed tomography & $\begin{array}{l}\text { - Enlarged RV, increased PA diameter of }>28 \mathrm{~mm}, \mathrm{PA} \text { : ascending aorta }>1 \\
\text { - } 73 \% \text { sensitive and } 84 \% \text { specific for the presence of PH at rest [44] } \\
\text { - Reflux of contrast into IVC and hepatic veins } \\
\text { - Chronic thromboembolic disease } \\
\text { - Signs of PVOD: interstitial edema with diffuse central ground-glass opacification } \\
\text { and thickening of interlobular septa } \\
\text { - Signs of PCH: diffuse bilateral thickening of the interlobular septa and presence of } \\
\text { small, centrilobular poorly circumscribed nodular opacities }\end{array}$ \\
\hline
\end{tabular}


Table 2 (continued)

\begin{tabular}{|c|c|}
\hline $\begin{array}{l}\text { Ventilation/perfusion (V/Q) } \\
\text { scan }\end{array}$ & $\begin{array}{l}\text { - More sensitive for CTEPH than computed tomography showing one or more } \\
\text { segmental or larger mismatched perfusion defects } \\
\text { - Tumor emboli: perfusion defects are numerous, symmetric, and more peripheral } \\
\text { - Less radiation, most cost-effective, and contrast-free than a CT chest }\end{array}$ \\
\hline $\begin{array}{l}\text { Cardiac magnetic resonance } \\
\text { imaging (MRI) }\end{array}$ & $\begin{array}{l}\text { - Cardiac MRI: Better in delineating RV anatomy, estimating RV end-diastolic } \\
\text { volume, RV mass, RV/LV interactions, and RV ejection fraction than } \\
\text { echocardiography [4] } \\
\text { - Limited use in intensive care unit }\end{array}$ \\
\hline \multicolumn{2}{|l|}{ Laboratory } \\
\hline Biomarkers & $\begin{array}{l}\text { - BNP }>100 \mathrm{pg} / \mathrm{mL}, \mathrm{NT}-\mathrm{proBNP}>900 \mathrm{pg} / \mathrm{mL} \text { : correlate with the degree of RV } \\
\text { dysfunction } \\
\text { - Good markers for monitoring response to treatment } \\
\text { - Increased troponins indicate acute myocardial injury (acute coronary syndrome, } \\
\text { myocarditis, acute PE, arrhythmias) and possibly predict poor outcomes in PAH }\end{array}$ \\
\hline \multicolumn{2}{|r|}{ ( } \\
\hline Pulmonary function testing & $\begin{array}{l}\text { - Normal spirometry (may have obstruction with COPD or restriction with ILD) } \\
\text { - Decreased DLCO }\end{array}$ \\
\hline CPET & $\begin{array}{l}\text { - Increased } \mathrm{VE} / \mathrm{VCO}_{2}: \text { more dead space and less ventilatory efficiency } \\
\text { - Steeper } \mathrm{VE} \text { to } \mathrm{VCO}_{2} \text { slope } \\
\text { - Lack of expected decrease in } \mathrm{Vd} / \mathrm{Vt} \\
\text { - Reduced peak } \mathrm{VO}_{2} \text { as reduced } \mathrm{O}_{2} \text { pulse } \\
\text { - } \mathrm{VO}_{2} \text { at anaerobic threshold is decreased, earlier lactic acidosis [39] }\end{array}$ \\
\hline
\end{tabular}

Definition of abbreviations: RV, right ventricular; PE, pulmonary embolism; P2, pulmonary valve closure sound; $\mathrm{PH}$, pulmonary hypertension; TR, tricuspid regurgitation; RVEF, right ventricular ejection fraction; TAPSE, tricuspid annular plane systolic excursion; LV, left ventricular; IVS, interventricular septum; PAH, pulmonary arterial hypertension; LVEF, left ventricular ejection fraction; PAP, pulmonary artery pressure; PA, pulmonary artery; PCWP, pulmonary capillary wedge pressure; PVR, pulmonary vascular resistance; RAP, right atrial pressure; DPG, diastolic pressure gradient; WU, Wood units; IVC, inferior vena cava; PVOD, pulmonary veno-occlusive disease; PCH, pulmonary capillary hemangiomatosis; CTEPH, chronic thromboembolic pulmonary hypertension; CT, computed tomography; MRI, magnetic resonance imaging; BNP, brain natriuretic peptide; NT-proBNP, N-terminal-proBNP; COPD, chronic obstructive pulmonary disease; ILD, interstitial lung disease; $\mathrm{DLCO}$, diffusing capacity for carbon monoxide; $\mathrm{VE} / \mathrm{VCO}_{2}$, minute ventilation relative to $\mathrm{CO}_{2}$ exhalation; $\mathrm{Vd} / \mathrm{Vt}$, dead space to tidal volume ratio; $\mathrm{VO}_{2}$, oxygen consumption

(bosutinib, ponatinib, lapatinib) has also been implicated as causing PAH [36, 73, 78]. PAH has also been described in patients with chronic myeloproliferative disorders [5, 30], and, along with pulmonary vasodilator therapy, treatment of the cancer and hematopoietic stem cell transplantation have been described to stabilize, improve, and even resolve the PAH [21, 54, 85].

PVOD is rare and characterized by obliteration of small pulmonary veins by fibrous intimal thickening and patchy capillary proliferation [63]. It may occur after hematopoietic stem cell transplantation [15] or in association with several chemotherapeutic classes, including alkylating agents (most notoriously with cyclophosphamide), antimetabolites, plant alkaloids and naturally occurring molecules, cytotoxic antibiotic and related molecules, cyclosporine, asparaginase, mycophenolate mofetil, anagrelide, interferon, antithymocyte globulin, and monoclonal antibodies [70]. PVOD portends a poor prognosis, and rapid referral should be made to a specialized PAH center for management and possible transplantation.

\section{Surgery in Patients with Preexisting PAH}

Patients with chronic PAH, who present for unrelated outpatient surgery, should receive careful perioperative care, preferably in an expert care facility familiar with and equipped for handling RV failure and cardiogenic shock [81]. A consideration should be made to switching oral PAH therapy to parenteral (inhaled or intravenous) ahead of time, as swallowing function and gut absorption may not be predictable perioperatively [23]. PAH patients carry a very large risk of 
mortality when surgery becomes emergent; and preoperative RV dysfunction, a higher NYHA functional class with worse exercise tolerance, and longer and more intricate surgery are associated with worse outcomes [68]. Induction of general anesthesia poses significant risks due to vasodilation and systemic hypotension, as well as adverse effects of positive pressure ventilation. Additively, surgery itself poses the usual risks, which patients with $\mathrm{PAH}$ are hemodynamically less equipped to tolerate. These surgical risks include fluid shifts, the need for continuous anesthetic use and neuromuscular blockade, and unfavorable positioning affecting lung volumes, all with resultant hypoventilation and hypoxemia that raise RV afterload [68]. In contrast, regional anesthetic techniques including nerve blocks and epidural anesthesia are better tolerated and preferentially recommended when possible [23].

\section{Epidemiology}

The prevalence of $\mathrm{PH}$ in the ICU is difficult to estimate, but the most common causes include left heart failure, pulmonary emboli, sepsis, and ARDS. In acute left heart failure, 3-9\% of admissions will have PH and subsequent RVF [35]. In severe COPD, approximately $3-5 \%$ have $\mathrm{PH}$ at baseline, and exacerbation or pneumonia may result in an ICU admission [13]. CTEPH occurs in $3.8 \%$ of patients suffering from an acute pulmonary embolism [67]. In general, WHO groups 2 to 5 are more common and thus more likely to require admission to higher-level care, primarily due to the risk of RVF [13].

\section{PAH}

Various national and international registries of patients with PAH (such as the REVEAL registry in the United States) have provided a framework for describing patient characteristics, natural history, and prognostication with data on treatment outcomes of PAH [59]. An important lesson from the current registries is the realization that subpopulations of $\mathrm{PAH}$ have significantly different outcomes and that overall survival has improved in the current era of new emerging treatments [58]. The prevalence of idiopathic (IPAH) and heritable PAH (HPAH) is estimated at 5-15 per one million in the general population $[43,52,58]$, while European registries estimate prevalence of PAH at 5-52 per one million $[2,47,66]$. The mean age of patients with idiopathic PAH has risen from 36 years to a mean age at diagnosis between 50 and 65 years in the current registries. In addition, the usual female predominance is less certain among older patients. Presentation to the ICU with RVF due to undiagnosed PAH has become increasingly rare and can be explained by improved awareness and earlier recognition of PAH. Furthermore, the newer PAH therapies have stabilized outpatient PAH and may have improved survival; thus ICU admissions are now more frequently due to triggering factors than decompensated PAH itself.

\section{Pathophysiology}

In order to treat $\mathrm{PH}$ with consequent RVF, it is important to understand the normal physiology of the RV. The thin-walled crescent-shaped RV differs substantially from the muscular and ellipsoidal left ventricle (LV). The RV performs six times less work than the LV while moving the same volume of blood [27, 41]. The RV pumps the entire systemic venous return into the highly compliant, low-resistance pulmonary circulation for gas exchange. In addition, the RV is easily distensible and can accommodate various changes in venous return due to posture, volume status, and respiration while maintaining adequate cardiac output [27].

The interaction of the forces transmitted from one ventricle to the other through the myocardium and pericardium is referred to as ventricular interdependence, and it is vital for ventricular synchrony [29, 41]. The pressure difference between the two ventricles is referred to as the transseptal gradient and is typically around $100 \mathrm{mmHg}$ [82]. The pressure in the LV is normally much higher than in the RV, and the interventricular septum (IVS) in its normal state 
A
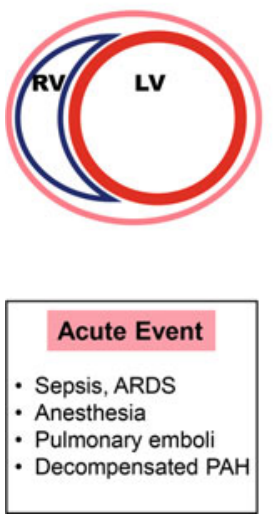

B
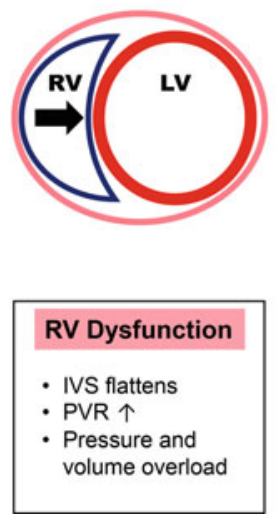
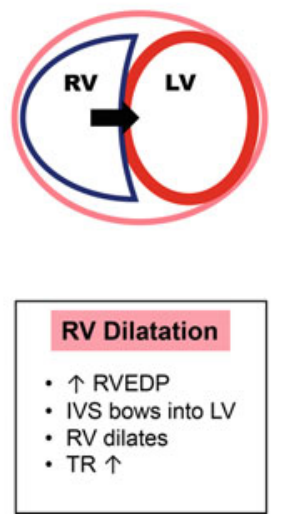

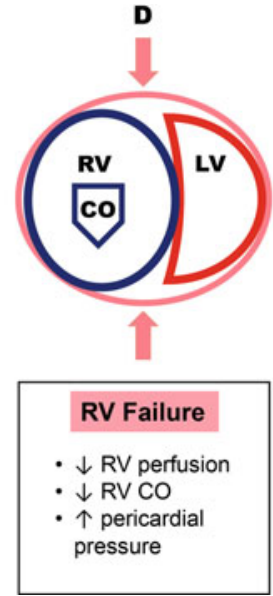

E
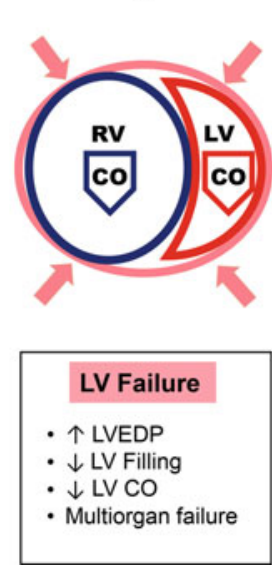

Fig. 1 Pathophysiology of right ventricular (RV) failure. An acute event (A) triggers right ventricular pressure and volume overload and dysfunction (B), causing flattening of the interventricular septum (black arrow). Subsequently, the right ventricular end-diastolic pressure begins to rise, the right ventricle begins to dilate $(\mathbf{C})$, and tricuspid regurgitation worsens. As the interventricular septum further bows into the left ventricle with concomitant pericardial constriction (pink arrows), the right ventricle becomes ischemic from decreased perfusion and begins to fail (D), dropping its cardiac output (blue arrow). The failing right ventricle then compromises left ventricular filling (E), causing rising left ventricular end-diastolic pressures and left ventricular failure. As systemic cardiac output drops (red arrow), ensuing hypotension results in multi-organ failure and possibly death. Definition of abbreviations: $\mathrm{RV}$, right ventricular; LV, left ventricle; $\mathrm{CO}$, cardiac output; ARDS, adult respiratory distress syndrome; PAH, pulmonary arterial hypertension; IVS, interventricular septum; PVR, pulmonary vascular resistance; RVEDP, right ventricular end-diastolic pressure; TR, tricuspid regurgitation; LVEDP, left ventricular end-diastolic pressure bulges into the RV, acting as a splint against which the RV contracts.

Cardiac output for both the RV and LV is governed by the same three factors: preload, afterload, and myocardial contractility. Coronary perfusion to the RV occurs during both systole and diastole, while LV perfusion occurs during diastole, thus making the RV dependent on systolic blood pressure. Perturbations in the normal physiology lead to RV dysfunction and eventually RVF (Fig. 1).

\section{Preload}

Both underfilling and overfilling of the RV can be detrimental. Decreased preload, as seen with an underfilled RV, leads to reduced stroke volume and cardiac output. Sepsis can exacerbate the underfilled RV with a low effective intravascular volume. Subsequent initiation of mechanical ventilation further increases intrathoracic pressures and negatively affects venous return, and the effect may be augmented with high levels of PEEP. Conversely, factors that excessively increase venous return result in volume overload for the RV, leading to tension and possible ischemia of its free wall, stretching of the tricuspid valve annulus, and flattening and bowing of the IVS into the LV. Thus, the RV cardiac output decreases and negatively affects LV filling and cardiac output as well. Conditions that manifest with an increased RV preload include tricuspid or pulmonic regurgitation, atrial septal defect, anomalous pulmonary venous return, and states of overall volume overload such as renal failure or after resuscitation for shock. Myocardial depression and decreased LV contractility often occur with sepsis in part due to oxygen supply and demand mismatch [40] and in part because of the effects of circulating cytokines such as tumor necrosis factor-alpha [8, 25]. As a result, the RV develops diastolic dysfunction as well as decreased contractility by the 
same mechanisms of myocyte hypoxia and circulating pro-inflammatory mediators. As sepsis resolves, both $\mathrm{LV}$ and $\mathrm{RV}$ function may normalize.

\section{Afterload}

The pulmonary vascular bed represents the afterload for the RV. In normal circumstances of increased oxygen demand, such as during exercise, the pulmonary circulation is able to both recruit and distend more vessels, thus realizing its great capacitance. Pulmonary blood flow and the ability to oxygenate are enhanced to match oxygen demand and rising systemic cardiac output. Conditions that affect the pulmonary circulation by increasing the pulmonary vascular resistance (PVR) include acute pulmonary embolism, RV outflow tract obstruction, hypoxic pulmonary vasoconstriction, pulmonary stenosis, and all chronic forms of PH. Sepsis causes vasoactive, microthrombotic, and inflammatory damage to the pulmonary circulation, raising the PVR [68]. In the ICU, volume loss (atelectasis, consolidation, pleural effusions, mainstem intubation) and overdistension (dynamic hyperinflation, high tidal volumes or PEEP) as well as acidemia, hypercarbia, hypoxemia, and hypothermia may also raise the PVR [82]. Alveolar hypoxia leads to hypoxic pulmonary vasoconstriction, decreased nitric oxide (NO), and increased endothelin production in the pulmonary circulation, causing further local vasoconstriction [25] Lastly, disseminated intravascular coagulation, commonly part of sepsis, may cause microthrombi to form in the pulmonary arterial tree [9].

\section{Contractility and Perfusion}

Conditions that manifest with decreased RV contractility include RV infarction, arrhythmias, cardiomyopathy, and sepsis. In conditions of acute $\mathrm{RV}$ failure, such as during a massive $\mathrm{PE}$, pressure in the pulmonary vascular bed rapidly increases, thus causing RV pressure to increase. Although the RV can dilate to accommodate the increased preload, its thin free wall precludes adequate acute adaptation to increased afterload. Once myocyte recruitment per the Frank-Starling mechanism has been maximized, any further increase in afterload will trigger a precipitous decrease in RV contractile function [27]. The dilated RV free wall experiences increased tension and ischemia, which further reduces free wall contractility. RV dilatation also results in stretching of the tricuspid annulus with subsequent tricuspid regurgitation (TR). The pericardial pressure also rises concurrently with the rising RV pressures and can constrain the cardiac chambers, further reducing their compliance, filling, and output [32].

Under excessive volume and pressure, the globular RV eventually pushes the IVS toward and into the LV cavity, compromising LV filling, stroke volume, and cardiac output. The resulting systemic hypotension further reduces coronary flow, RV perfusion, and RV cardiac output [51]. Thus, the cycle propagates, with a failing RV compromising LV function, and a struggling LV increasing the demand on the RV thus leading to worsened RV function followed closely by multi-organ hypoperfusion and failure.

\section{Chronic PH}

In cases of chronic PH (of either pre- or postcapillary etiology), the RV responds to increased pressures in the pulmonary vascular bed with progressive hypertrophy, thus maintaining cardiac output at rest over long periods of time [35]. In the end stage, the RV dilates, which leads to worsened TR and ultimately decreased cardiac output. Acute decompensation of chronic pulmonary hypertension may be clinically indistinguishable from acute RVF.

$\mathrm{PAH}$ in particular is a progressive vasculopathy, in which the pulmonary vascular bed undergoes intimal and smooth muscle hypertrophy, adventitial remodeling complicated with fibrosis, in situ vasoconstriction, and microthrombosis [42]. The histopathologic hallmark of $\mathrm{PAH}$ is the plexiform lesion, which consists of obliterative endothelial cell proliferation and vascular smooth muscle cell hypertrophy in small 
pre-capillary pulmonary arterioles. These changes over time cause an increase in pulmonary artery pressures and subsequently PVR. With a gradual rise in PVR, the RV can adapt by means of hypertrophy in order to preserve its cardiac output and ventriculoarterial coupling [64].

\section{Clinical Features}

PH may be suspected due to presenting signs and symptoms or, not infrequently, due to incidentally noted features on a diagnostic test (Table 2) such as electrocardiogram, echocardiography (Fig. 2), or other imaging (Fig. 3). Cardinal symptoms of volume overload such as jugular venous distention, peripheral edema, and ascites indicate RVF, also referred to as cor pulmonale. In the absence of an established diagnosis, presenting clinical features may point in the direction of an underlying cause of PH. For example, obesity and awake alveolar hypoventilation may indicate obesity hypoventilation syndrome, inspiratory crackles and clubbing may point toward interstitial lung disease, while sclerodactyly and digital ulcers may suggest systemic sclerosis.

As the pulmonary artery enlarges further, it may exert mass effect on adjacent structures to cause wheezing from compression of airways, hoarseness from compression of the recurrent laryngeal nerve, or cardiac ischemia from compression of the left main coronary artery [23, 68]. A massively enlarged pulmonary artery is also at risk for dissection or spontaneous rupture, potentially causing cardiac tamponade or dramatic hemodynamic collapse and death [23].

On cardiac examination, presence of a right parasternal lift, an accentuated pulmonary component of a second heart sound (loud P2), a rightsided third heart sound (S3), pansystolic murmur of TR, or a diastolic murmur of pulmonary regurgitation may all raise suspicion for $\mathrm{PH}$, while jugular venous distention, hepatic enlargement and tenderness, and hepatojugular reflux may indicate right heart failure. Signs of left-sided heart failure may include a left-sided third heart sound (S3), crackles on lung examination, displaced apical impulse, or cool cyanotic extremities.

\section{Diagnosis}

Certain conditions may initially present as $\mathrm{PH}$ in the ICU but then return to normal pulmonary pressures days to weeks after treatment. Airway exacerbation caused by underlying COPD or ILD, acute decompensated left heart failure, pulmonary embolism, and sepsis are prime examples. A subset of these patients already has or will develop $\mathrm{PH}$ as a sequela of their disease. Chronic $\mathrm{PH}$ is often a comorbidity that becomes destabilized by an acute insult or critical illness. If chronic PH is suspected during an ICU admission, an attempt should be made to confirm the diagnosis adequately and classify it appropriately, for pulmonary vasodilator therapy could be part of the treatment.

Detection of PH in the ICU centers around two main tools: echocardiography and pulmonary artery catheterization. A thorough history may provide information regarding risk factors for heart disease, pulmonary emboli or chronic $\mathrm{PH}$, as well as symptoms that preceded ICU admission. Other studies (Table 2) may also be suggestive of $\mathrm{PH}$.

\section{Echocardiography}

Echocardiography is a dependable tool for screening and serial follow-up of pulmonary pressures and both left and right heart function in outpatient $\mathrm{PH}$. Its role in the ICU is indispensable in quick and noninvasive measurement of the pulmonary artery systolic pressure (PASP), assessment of RV structure and function, estimation of volume status, evaluation of TR severity, evaluation of the pericardium, and search for causes of $\mathrm{PH}$ such as intracardiac shunts and left heart disease [60] (Table 2). Measuring the PASP depends on the peak TR jet Doppler velocity plus an estimate of the right atrial pressure [45]. An estimated PASP greater than $40 \mathrm{mmHg}$ or a peak TR jet velocity $\geq 3 \mathrm{~m} / \mathrm{s}$ is predictive of $\mathrm{PH}$ [45]. The tricuspid 

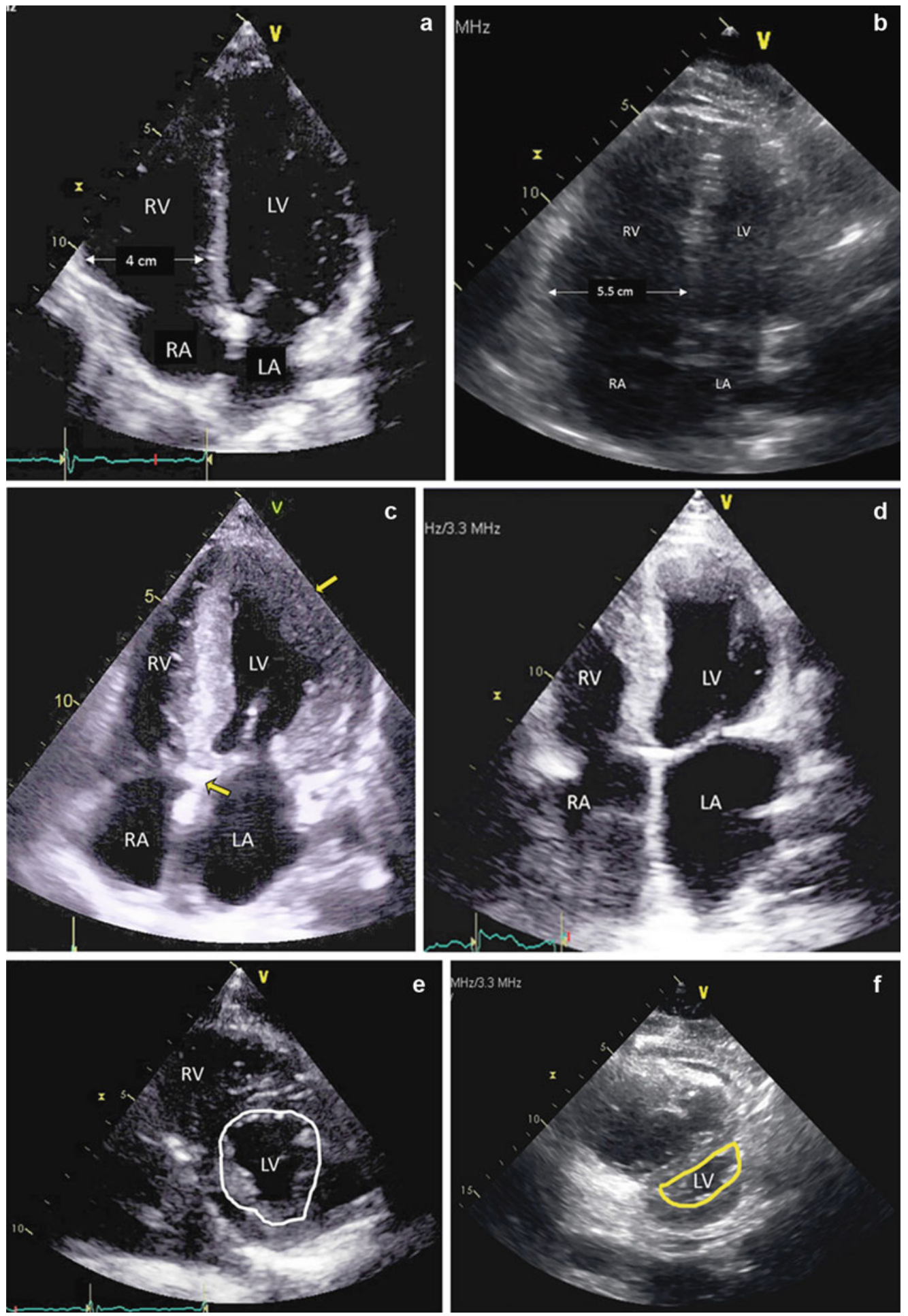

Fig. 2 (continued) 

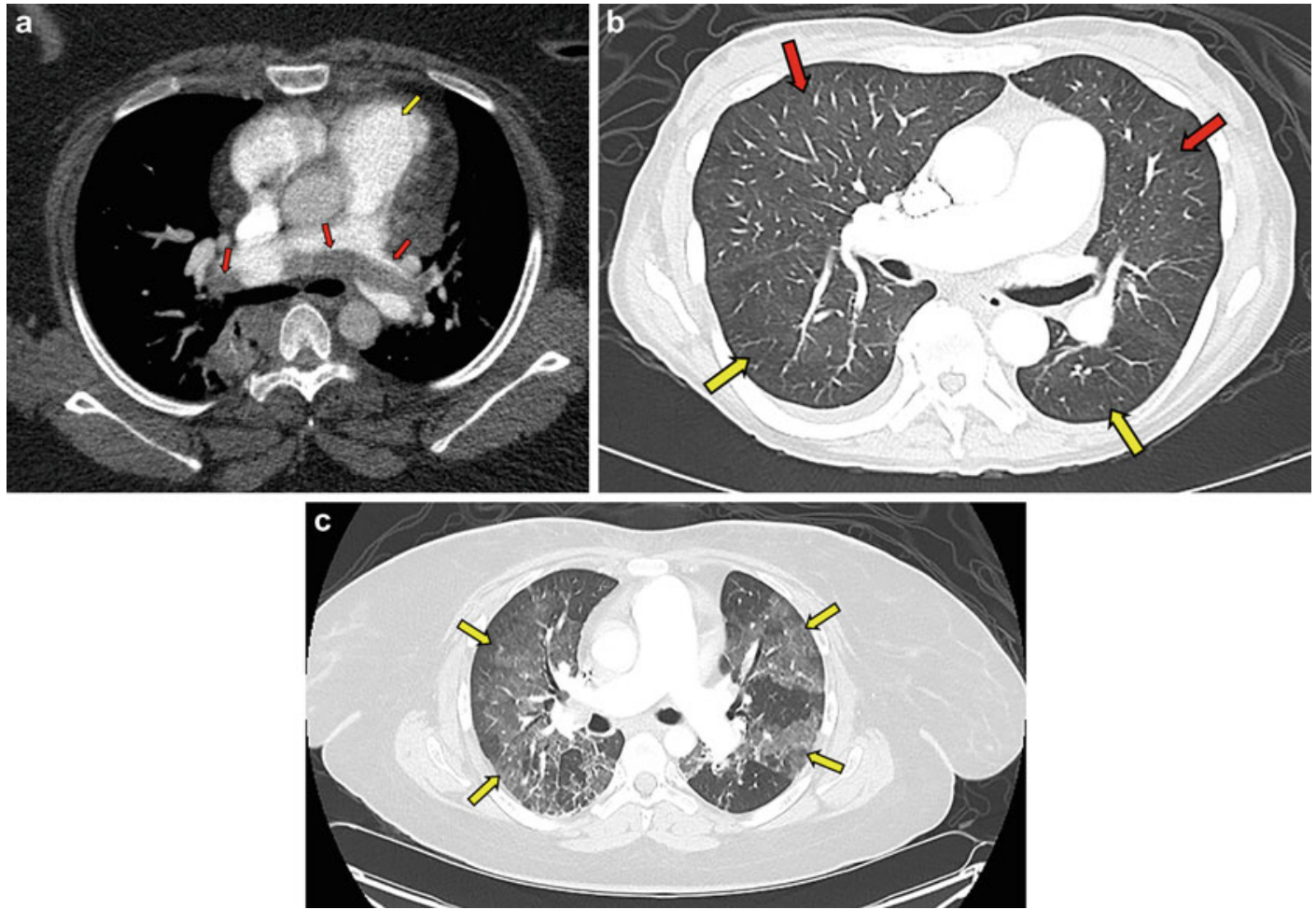

Fig. 3 CT imaging of pulmonary hypertension. (a) Saddle embolus (red arrows) that bridges across the pulmonary artery from the heart as it divides into right and left main pulmonary arteries with enlarged pulmonary artery (yellow arrow). (b) Myelofibrosis with severe pulmonary arterial hypertension (a mean pulmonary artery pressure of 49 , pulmonary capillary wedge pressure of 9 , pulmonary vascular resistance of 9.4) with CT angiogram revealing no pulmonary embolism but prominent enlarged main pulmonary artery with mosaic attenuation (yellow arrows, decreased

annular plane systolic excursion (TAPSE) should be about $2.4-2.7 \mathrm{~cm}$, while values below $1.8 \mathrm{~cm}$ have been shown to correlate well with a decreased stroke volume index and RV ejection fraction, as well as increased hospitalizations for RHF and decreased survival in those with PAH [86]. Higher PASPs often imply that the PH is lung perfusion; red arrow, increased lung perfusion) within lung parenchyma. (c) Ovarian cancer (status post five cycles of vinblastine, cisplatin, cyclophosphamide, bleomycin, doxorubicin, and etoposide) with hypoxic respiratory insufficiency, new bilateral infiltrates, and pulmonary hypertension on echocardiogram thought to be related to bleomycin toxicity. Oxygen was limited due to concern for bleomycin toxicity, and she was treated with high-dose steroids and empiric antimicrobial therapy. Definition of abbreviations: CT, computed tomography

chronic, and the RV may have had time to hypertrophy, or there is acute-on-chronic PH. Dilation or hypokinesis of the RV or a flattened (or bowing) IVS suggests RV pressure and volume overload. Echocardiography also rules out or confirms pericardial effusion, measures cardiac chamber sizes,
Fig. 2 Transthoracic echocardiogram. Four-chamber view in diastole of a normal right ventricle base (a) measuring $4 \mathrm{~cm}$ (should be less than $4.2 \mathrm{~cm}$ ), dilated right ventricle (b) in pulmonary hypertension, restrictive cardiomyopathy (c) in an amyloid in patient with thickened septum (yellow arrow between RA and LA) and left ventricular cavity wall (yellow arrow next to LV), and diastolic heart failure (d) with enlarged left atrium and ventricle.
Parasternal view with normal right and left ventricle (e) and dilated right ventricle (f) with D-shaped left ventricular (yellow outline) suggestive of volume and pressure overload (Echocardiographic images courtesy of Juan LopezMattei, MD, MD Anderson Cancer Center, Houston, Texas). Definition of abbreviations: LA, left atrium; LV, left ventricle; RA, right atrium; RV right ventricle 
and may reveal constrictive physiology and/or the presence of infiltrative cardiomyopathy.

\section{Right Heart Catheterization (RHC)}

A RHC procedure is done to confirm elevated pulmonary artery pressures and aids in classifying $\mathrm{PH}$, grading its severity, and assessing for vasoreactivity. Pressures in right-sided heart chambers and the pulmonary artery can be directly measured, while the left atrial pressure can be estimated by measuring the pulmonary capillary wedge pressure (PCWP). In addition, cardiac output, cardiac index, as well as systemic vascular resistance (SVR) and PVR can be calculated. Vasoreactivity studies with NO, adenosine, or prostacyclins may be performed at baseline to evaluate the responsiveness of the pulmonary circulation and also provide prognostic information, but they should be avoided in patients with significant evidence of post-capillary $\mathrm{PH}$ [60]. In those who respond, calcium channel blockers could be a potential treatment option.

\section{Management}

Regardless of the etiology, the natural progression of PH inevitably leads to RVF. Treatment directed toward the underlying cause is important; however, the exact trigger may not always be obvious. Strategies are crucial to optimize preload and cardiac contractility, enhance systemic arterial perfusion, and reduce right ventricular afterload. In cases of new or decompensated PAH, coordination of care and potential transfer to a specialized PH center should be arranged early, if possible.

In order to maximize hemodynamic recovery in RVF, a few overarching principles need to be considered and optimized concurrently (Fig. 4). It is useful to have an arterial catheter and a central venous catheter in the internal jugular or subclavian position for close hemodynamic monitoring. These allow for serial measurements of central venous pressure (CVP), arterial blood gases, central venous oxygen saturation $(\mathrm{ScvO} 2)$, and lactic acid levels. A rising lactic acid and a dropping or low $\mathrm{ScvO} 2$ level can be used as surrogates for end-organ hypoperfusion from a decreasing cardiac output. Other signs of acute end-organ injury may include elevated serum creatinine or decreasing urine output indicating renal insufficiency, while elevated liver enzymes or new coagulopathy may suggest liver injury. It is important to note that venous congestion seen with an overdistended RV and that from reduced cardiac output from RV underfilling may have similar presentations, which necessitates accurate measurement of CVP. In certain complex cases, such as a mixed shock state, a case where trending PVR and PCWP are important, or post cardiac surgery, a pulmonary artery catheter may be necessary to optimize management of RVF.

\section{Stabilize and Identify Triggers}

Among the first priorities of treating RVF is proper identification and control of exacerbating factors. Sepsis, pulmonary embolism, and acute coronary syndrome are notorious culprits of $\mathrm{PH}$ in the ICU. In patients with septic shock, empiric antimicrobial therapy and identification of infectious etiology are vital. Institution of high-flow oxygen or noninvasive positive pressure ventilation may help stabilize patients with hypoxic or hypercapnic respiratory insufficiency. Patients with pulmonary embolism and hemodynamic compromise should be evaluated for systemic thrombolytics, and in nonresponders or those who cannot receive them, surgical embolectomy, catheter-directed thrombolysis, as well as mechanical circulatory support devices such as extracorporeal membrane oxygenation (ECMO) and right ventricular assist devices (RVAD) can be considered when appropriate [48, 56, 76, 88]. Ensuring that RV ischemia is not a result of an acute coronary syndrome is important since rapid revascularization by percutaneous coronary intervention could be necessary to restore RV perfusion. Prompt cessation of any pharmacologic agents that may have precipitated $\mathrm{PH}$, such as tyrosine kinase inhibitors, chemotherapy, 

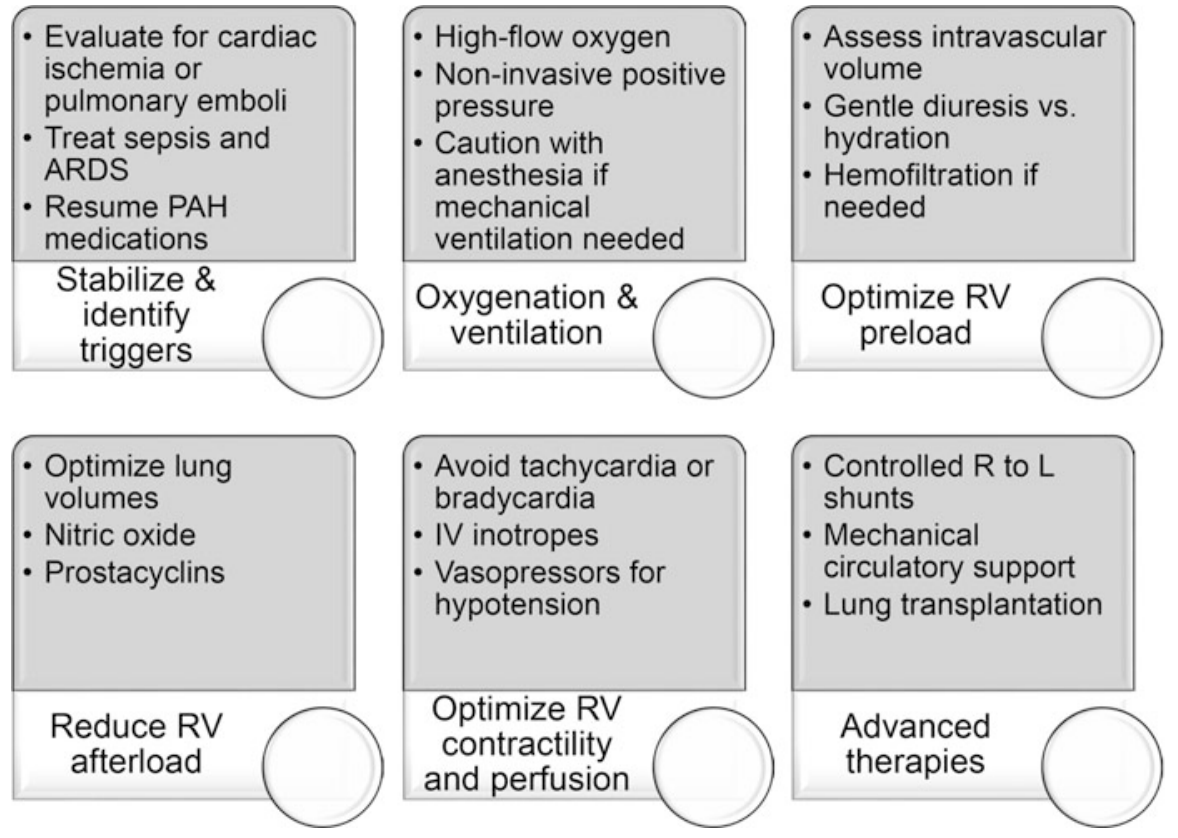

Fig. 4 Management of right ventricular failure. Strategies to stabilize should be taken swiftly and concomitantly rather than sequentially. Consultation and transfer of patients with pulmonary arterial hypertension (PAH) to a specialized pulmonary hypertension center should be

anorexigens, or illicit drugs, is imperative. The use of steroids and/or nebulized therapy could be a part of the treatment for exacerbations of COPD or ILD. In cases of PAH therapy withdrawal, restarting pulmonary vasodilators is crucial. In those with suspected CTEPH, review with and/or referral to a specialized surgical center for consideration of pulmonary endarterectomy is imperative. Finally, continuous vigilance to correct metabolic abnormalities including acidosis, hypoxemia, hypercapnia, hypothermia, and hypocalcemia is vital to sustain RV contractility negatively affected by these factors.

\section{Optimize Preload}

Patients with RV failure, especially those with chronic PH, may be preload-dependent, so ensuring adequate RV filling without allowing overload is crucial to maintain RV function. Using invasive considered. Definition of abbreviations: ARDS, adult respiratory distress syndrome; $\mathrm{PAH}$, pulmonary arterial hypertension; RV, right ventricular; IV, intravenous; R, right heart; L, left heart

or noninvasive measurements of CVP and cardiac output is necessary to determine optimal RV filling. Aggressive volume resuscitation or vigorous diuresis should be discouraged, and cautious fluid replacement or gradual diuresis with monitoring should be considered especially since concomitant hypotension may be present. Aiming for a CVP of around $10-14 \mathrm{mmHg}$ is usually recommended.

Often a dysfunctional RV may be distended and overloaded, requiring volume removal in addition to providing inotropic support. If the kidneys are functioning, diuresis with intravenous loop diuretic agents can be tried initially, using careful continuous infusion in case of hypotension. As heart failure induces a hyperaldosterone state, addition of spironolactone, barring any contraindications, such as hyperkalemia, may be helpful [68]. Furthermore, dopamine has been used in low doses to improve renal perfusion, thus aiding in natriuresis [20, 24]. Lastly, 
tolvaptan, an oral selective vasopressin antagonist, has been studied with promising results [84], but needs further validation. The goal is to attain 1-1.5 L of net negative fluid balance per day to avoid large hemodynamic swings and any acute drastic decrease in RV preload. In cases of profound RVF leading to dense renal injury (or acute or chronic renal insufficiency of other etiologies), ultrafiltration through continuous renal replacement therapy may be required.

\section{Oxygenation and Ventilation}

Oxygen is the most important physiologic vasodilator of the pulmonary system, and it may ameliorate hypoxic pulmonary vasoconstriction and reduce PVR. High-flow oxygen may be especially useful in avoiding or preventing intubation. In those with underlying lung disease or concomitant left heart dysfunction, noninvasive positive pressure therapy may help reduce the labor of breathing and improve ventilation. Positive airway pressure, however, can negatively affect RV function. In those with hemodynamic instability, altered mentation, or persistent hypoxemia, intubation with mechanical ventilation may be unavoidable despite its risks of significant metabolic and hemodynamic adverse effects. Hypotension with induction is common from sedating agents and neuromuscular blockade, and it may also occur from withdrawal of the potent sympathetic drive when work of breathing is relieved. Lastly, placing the patient in the supine position worsens hypoxemia through physiologic shunting. Therefore, in cases of decompensated $\mathrm{PH}$ and RVF, intubation should be avoided if at all possible. When intubation is necessary, precautions must be taken to prevent hypotension, acidosis, hypercarbia, and hypoxemia. Typically, medications that are considered relatively safe to use include opiates, benzodiazepines, etomidate, and ketamine at the lowest effective doses. If possible, propofol and paralysis should be avoided to prevent hypotension or, if needed, should be co-administered with a vasopressor empirically to prevent hypotension. It is also wise to have a vasopressor infusion prepared and ready to administer if sudden hypotension occurs.

\section{Reduce Right Ventricular (RV) Afterload}

Reduction of RV afterload essentially implies reduction of PVR, and when possible, nonpharmacologic strategies to reduce RV afterload should be instituted rapidly. In those who are mechanically ventilated, a high PEEP may increase PVR and decrease venous return thereby affecting preload, so limiting plateau and PEEP pressures is important. Attaining and maintaining optimal lung volumes is crucial as both overdistension and atelectasis of lung units increase the PVR. Atelectatic alveoli compress extraalveolar vessels, resulting in an increase in PVR. Overdistension of alveoli compresses intraalveolar vessels, still causing an increase in PVR [11]. Other helpful strategies include drainage of significant pleural effusions, sedation to prevent ventilator dyssynchrony, and appropriate positioning of the patient (including proning).

Pharmacologic therapy will almost invariably be required. Significant improvement in RV function can be achieved only with significant decrease in PVR [91]. Inhaled pulmonary artery vasodilators are effective by directly lowering the PVR, and the improved perfusion then optimizes ventilation/perfusion matching in well-ventilated parts of lung [17]. As hypoxemia improves, PVR is reduced further. Inhaled $\mathrm{NO}$ can easily be administered in either ventilated or non-ventilated patients in doses of 10-40 ppm. NO is often used in severe ARDS and also perioperatively for cardiac surgery in heart failure. Prolonged use at high doses, though, can cause accumulation of methemoglobin as well as other oxidants such as $\mathrm{NO}_{2}$ [89]. In addition, abrupt withdrawal of NO may cause devastating rebound of PH [12]; therefore it needs to be weaned slowly.

Much of the evidence for use of medications in PAH pertains to chronic outpatient management rather than critical care in an ICU setting. Because of the lack of robust evidence, most current practices are specific to individual preferences, facility 
culture, and expert opinion. Moreover, a large majority of targeted PAH medications that are revolutionizing outpatient $\mathrm{PAH}$ treatment are not indicated in the majority of patients with RVF without PAH. For those patients with chronic PAH, all chronic pulmonary vasodilator therapy should be resumed. In patients with decompensated PAH and RVF, intravenous or inhaled prostanoids should be emergently initiated, and ideally invasive monitoring should be started to guide titration based on hemodynamic measures. Concurrent inotropic support with dobutamine or dopamine, as well as vasopressor support with norepinephrine or vasopressin, may be necessary during this process to maintain hemodynamic stability. Targets of end-organ perfusion such as lactic acid, $\mathrm{ScvO} 2$, urine output, and liver function tests should also be serially monitored. Abrupt discontinuation of IV prostacyclin can lead to rapid deterioration from rebound $\mathrm{PH}$; therefore interruptions should be carefully anticipated and avoided. Longer-acting analogues of prostacyclin (iloprost and treprostinil) can be administered through nebulization [10]. Inhaled milrinone has also been studied alone as well as in combination with inhaled prostacyclin in the context of cardiovascular surgery, but it is not widely used at this time $[6,16$, 34]. Sildenafil, a phosphodiesterase-5 inhibitor, can be used in treating acute cardiogenic RV shock from PH [22]. Percutaneous balloon pulmonary angioplasty (BPA) is an alternative option to pulmonary endarterectomy in CTEPH and carries a significant risk of reperfusion injury, embolism, and pulmonary artery perforation [1]. Therefore, these procedures are best performed at specialized centers.

\section{Optimize RV Contractility and Perfusion}

Treating systemic hypotension should be one of the earliest steps in management of RV failure. Vasopressors must be initiated rapidly in order to restore adequate mean arterial pressure, but those that raise SVR and not PVR should be preferentially selected. Norepinephrine is used as the first- line agent and does not significantly raise PVR [46]. Vasopressin acts through non-adrenergic V1 receptors and is either PVR neutral or potentially may even lower it slightly [68].

Milrinone, a phosphodiesterase-3 inhibitor, and to a lesser extent dobutamine, a beta agonist, decrease the PVR while increasing contractility. Both agents, but especially milrinone, cause systemic vasodilation that can result in or exacerbate hypotension. Therefore, while necessary to improve forward flow through the pulmonary vasculature with inotropic agents, norepinephrine or vasopressin may be concurrently necessary to maintain an adequate SVR. Dobutamine is typically the first choice for inotropic support, but dopamine and milrinone are also options. All catecholamines carry a risk of causing or worsening tachycardia, and milrinone may also cause atrial arrhythmias. Aside from cases of concomitant left heart failure, digoxin does not have much of a role in the treatment of RVF. Levosimendan, a calcium sensitizer and phosphodiesterase-3 inhibitor, enhances cardiac contractility without increasing myocardial oxygen demand, but it may result in systemic and pulmonary vasodilation [68] and atrial arrhythmias. In a recent meta-analysis, levosimendan showed significant increase in TAPSE and ejection fraction, with decrease in PASP and PVR [69].

The preservation and restoration of sinus rhythm are also a high priority with an optimal heart rate range of $80-100$ beats per minute. Bradycardia seen with conduction abnormalities can reduce RV stroke volume by allowing more time for TR, while supraventricular tachycardias (SVT) can reduce RV stroke volume by decreasing the time for RV filling; neither are well tolerated and should be treated expeditiously if they occur [33]. Direct current cardioversion should be done early to restore normal sinus rhythm, ventricular filling, and cardiac output. Although amiodarone has a slower onset of action, it does not have negative inotropic effects, and is beneficial for maintaining sinus rhythm after cardioversion. When an SVT involves the atrioventricular node, adenosine may be considered prior to cardioversion [68]. The use of beta-blockers and calcium channel blockers is controversial and, if 
pursued, should be done cautiously, since both may have a detrimental effect on the RV.

Malignant arrhythmias such as ventricular tachycardia, torsades de pointes, and ventricular fibrillation can occur for variety of reasons. Triggering factors for arrhythmias, including electrolyte abnormalities, metabolic disturbances (thyroid disease), myocardial ischemia, and medication interactions (QTC prolongation), should be uncovered and treated.

\section{Pharmacologic Treatment Modalities}

Pharmacologic therapies and their properties are detailed in Table 3. The vasopressors recommended for use are typically norepinephrine and vasopressin, but phenylephrine may be considered. The inotropes include dobutamine, dopamine, and epinephrine, while the inodilators include milrinone and levosimendan. In addition, in order to decrease RV afterload, pulmonary vasodilators, most commonly $\mathrm{NO}$, are a crucial part of acute RVF treatment.

\section{Nitric oxide}

Inhaled NO is very short acting and is quickly inactivated in the pulmonary capillaries, causing little to no systemic effects [93]. Thus, NO or its donors (inhaled nitroglycerin or sodium nitroprusside) rapidly and effectively lower the PVR and can be easily administered as an inhaled gas. Several targeted PAH agents exploit the NO pathway for treatment of PAH.

\section{Prostacyclins}

Inhaled prostacyclins, iloprost and treprostinil, are both options for PH. Prostacyclin was the first agent used and was shown to improve outcomes in PH, RV dysfunction, and refractory hypoxemia after cardiovascular surgery [18], and it may be more economical and more available than inhaled NO in many ICUs.

\section{Other pulmonary vasodilators}

In the outpatient setting, endothelin receptor agonists (bosentan, ambrisentan, macitentan), phosphodiesterase-5 inhibitors (sildenafil and tadalafil), the soluble guanylate cyclase agonist (riociguat), as well as oral prostanoids (selexipag, Orenitram) are all widely used for PAH. Combination therapy is now the standard for a significantly lower risk of clinical failure events. However, these oral agents do not have a role in acute management of RVF in the ICU.

\section{Nonpharmacologic Treatment Modalities}

\section{Balloon Atrial Septostomy (BAS)}

An artificial surgical atrial septal right-to-left shunt can be created in order to decompress the right heart chambers, thus decreasing RV wall stress, volume, and pressure overload and increasing LV preload and cardiac output. BAS is indicated in patients with functional class IV symptoms with RHF from $\mathrm{PH}$ who are optimized and refractory to all other medical therapy. In these cases, BAS can serve either as a bridge to lung transplantation or as a palliative care measure [77]. Since BAS carries a risk of further oxygen desaturation and a higher risk of complications in patients with baseline mean RAP $>20 \mathrm{mmHg}$ or oxygen saturation at rest of $<85 \%$ on room air [23], it should be avoided in these cases.

\section{Mechanical Circulatory Support}

Mechanical circulatory support should be considered in those with persistent RVF who are optimized on medical therapy. Transfer to a specialized center is essential, and device selection is based on etiology of RVF and expected duration of mechanical support. The timing of placement ideally occurs prior to end-organ damage, for multi-organ failure is the leading cause of death in unsuccessful cases [35]. RVF due to RV myocardial infarction, acute pulmonary embolism, following left ventricular assist device (LVAD) implantation, or primary graft failure after heart transplantation are clinical scenarios in which acute mechanical circulatory support may be required.

In cases of primary pulmonary etiology, ECMO is the most appropriate therapy, as an 
Table 3 Pharmacotherapy available to treat pulmonary hypertension or decompensation of right ventricular failure

\begin{tabular}{|c|c|c|c|}
\hline Agent (receptor \& MOA) & $\begin{array}{l}\text { Primary goal } \\
\text { Secondary effect }\end{array}$ & Usual dosing & $\begin{array}{l}\text { Adverse effects } \\
\text { other notes }\end{array}$ \\
\hline \multicolumn{4}{|l|}{ Increased inotropy } \\
\hline $\begin{array}{l}\text { Dopamine } \\
\text { Low to medium dose }(D, \beta 1>\alpha 1) \\
\text { High dose }(\alpha 1=\beta 1, D)\end{array}$ & $\begin{array}{l}\uparrow \text { Inotropy } \\
\uparrow \text { Renal perfusion } \\
\uparrow \mathrm{CI} \\
\uparrow \text { SVR at higher } \\
\text { doses }\end{array}$ & $\begin{array}{l}2-10 \mu \mathrm{g} / \mathrm{kg} / \mathrm{min} \\
10-50 \mu \mathrm{g} / \mathrm{kg} / \mathrm{min}\end{array}$ & $\begin{array}{l}\text { Tachycardia } \\
\text { Arrhythmias } \\
\uparrow \text { PVR at higher doses }\end{array}$ \\
\hline Dobutamine $(\beta 1>\beta 2)$ & $\begin{array}{l}\uparrow \text { Inotropy } \\
\uparrow \mathrm{CI}, \downarrow \text { PVR }\end{array}$ & $2.5-15 \mu \mathrm{g} / \mathrm{kg} / \mathrm{min}$ & $\begin{array}{l}\text { Tachycardia, arrhythmias } \\
\text { Hypotension ( } \downarrow \text { SVR) }\end{array}$ \\
\hline Epinephrine $(\alpha 1=\beta 1>\beta 2)$ & $\begin{array}{l}\uparrow \mathrm{CI} \\
\downarrow \mathrm{PVR}, \uparrow \mathrm{SVR}\end{array}$ & $0.1-0.5 \mu \mathrm{g} / \mathrm{kg} / \mathrm{min}$ & Tachycardia, arrhythmias \\
\hline Milrinone $\left(\mathrm{PDE}_{3} \mathrm{I}\right)$ & $\begin{array}{l}\uparrow \text { Inotropy } \\
\uparrow \mathrm{CI}, \downarrow \text { PVR }\end{array}$ & $\begin{array}{l}\text { Load: } 50 \mu \mathrm{g} / \mathrm{kg} \\
0.25-0.75 \mu \mathrm{g} / \mathrm{kg} / \mathrm{min}\end{array}$ & $\begin{array}{l}\text { Tachycardia, arrhythmias } \\
\text { Hypotension ( } \downarrow \text { SVR) }\end{array}$ \\
\hline $\begin{array}{l}\text { Levosimendan }\left(\mathrm{Ca}^{2+} \text { sensitizer and }\right. \\
\left.\mathrm{PDE}_{3} \mathrm{I}\right)\end{array}$ & $\begin{array}{l}\uparrow \text { Inotropy } \\
\uparrow \mathrm{CI}, \downarrow \text { PVR }\end{array}$ & $\begin{array}{l}\text { Load: } 6-12 \mu \mathrm{g} / \mathrm{kg} \\
0.05-0.2 \mu \mathrm{g} / \mathrm{kg} / \mathrm{min}\end{array}$ & $\begin{array}{l}\text { Tachycardia, arrhythmias } \\
\text { Hypotension }(\downarrow \text { SVR) }\end{array}$ \\
\hline Digitalis & $\begin{array}{l}\uparrow \text { Inotropy } \\
\downarrow \text { HR }\end{array}$ & $\begin{array}{l}\text { Rhythm control in atrial } \\
\text { fibrillation }\end{array}$ & $\begin{array}{l}\text { AV blocks } \\
\text { Use when } \downarrow \text { LVEF }\end{array}$ \\
\hline \multicolumn{4}{|c|}{ Decreased pulmonary vascular resistance } \\
\hline Inhaled NO & $\downarrow$ PVR & $10-40 \mathrm{ppm}$ & $\begin{array}{l}\text { Methemoglobinemia } \\
\text { Hypotension }\end{array}$ \\
\hline $\begin{array}{l}\text { Inhaled prostanoids } \\
\text { Iloprost } \\
\text { Treprostinil }\end{array}$ & $\downarrow$ PVR & $\begin{array}{l}2.5-5 \mu \mathrm{g} 6-9 / \text { day } \\
6-54 \mu \mathrm{g} \text { QID }\end{array}$ & $\begin{array}{l}\text { Hypotension, headache } \\
\text { Flushing } \\
\text { Jaw pain }\end{array}$ \\
\hline $\begin{array}{l}\text { IV/SC prostanoids } \\
\text { Epoprostenol (IV) } \\
\text { Treprostinil (IV/SC) }\end{array}$ & $\downarrow \mathrm{PVR}$ & $1-40 \mathrm{ng} / \mathrm{kg} / \mathrm{min}$ & $\begin{array}{l}\text { Hypotension, headache } \\
\text { Flushing, jaw pain }\end{array}$ \\
\hline Sildenafil IV/SL (PDE 5 I) & $\downarrow$ PVR & $5-20 \mathrm{mg}$ TID & Hypotension \\
\hline \multicolumn{4}{|l|}{ Increased mean arterial pressure } \\
\hline Norepinephrine $(\alpha 1>\beta 1)$ & $\begin{array}{l}\uparrow \mathrm{SVR} \\
\uparrow \mathrm{CI}\end{array}$ & $0.01-3 \mu / \mathrm{kg} / \mathrm{min}$ & $\begin{array}{l}\text { Tachycardia, arrhythmias } \\
\text { PVR neutral at low doses } \\
\uparrow \text { PVR at higher doses }\end{array}$ \\
\hline Vasopressin (V1, D) & $\uparrow \mathrm{SVR}$ & $0.01-0.03 \mathrm{IU} / \mathrm{min}$ & $\begin{array}{l}\text { PVR, CI neutral } \\
\text { Heart rate neutral }\end{array}$ \\
\hline Phenylephrine $(\alpha 1)$ & $\uparrow \mathrm{SVR}$ & $0.5-5 \mu \mathrm{g} / \mathrm{kg} / \mathrm{min}$ & $\begin{array}{l}\downarrow \mathrm{CI}, \uparrow \text { PVR } \\
\text { Reflex bradycardia }\end{array}$ \\
\hline
\end{tabular}

Medications are grouped by their primary goal effect. Pink, increased inotropy; blue, decreased pulmonary vascular resistance; yellow, increased mean arterial pressure.

Definition of abbreviations: $\mathrm{PH}$, pulmonary hypertension; RVF, right ventricular failure; MOA, mechanism of action; D, dopamine receptor; $\beta 1$, beta-1 adrenergic receptor; $\beta 2$, beta- 2 adrenergic receptor; $\alpha 1$, alpha- 1 adrenergic receptor; $P D E_{3} I$, phosphodiesterase-3 inhibitor; NO, nitric oxide; IV, intravenous; SC, subcutaneous; SL, sublingual; PDE 5 , phosphodiesterase-5 inhibitor; V1, vasopressin-1 receptor; PVR, peripheral vascular resistance; CI, cardiac index; SVR, systemic vascular resistance; HR, heart rate; QID, four times a day; TID, three times a day; IU, international units; ppm, parts per million; $\mathrm{AV}$, atrioventricular; $\mathrm{LVEF}$, left ventricular ejection fraction

right ventricular assist device (RVAD) may further increase PASP and potentially precipitate pulmonary hemorrhage [49, 55]. An RVAD is more appropriate when RHF is from an isolated RV etiology. Advanced heart failure from an LV etiology usually requires an LVAD, while biventricular failure or RHF following LVAD implantation or heart transplantation may necessitate placement of a biventricular assist device or a total artificial heart device [49, 55]. The use of permanent mechanical support devices in RHF caused by chronic $\mathrm{PH}$ is contentious, off-label and needs further study $[49,55]$. 


\section{Transplantation}

Cardiac transplant is the ultimate treatment for refractory RVF [35]. Of note, presence of an RVAD support before heart transplantation is associated with a higher mortality [53].

In those with PAH, referral should be made before severe RHF develops. Patients with PVOD and PCH have the worst prognosis and should be listed for transplantation at diagnosis, given the lack of treatment options [23]. Patients with PAH associated with connective tissue disease also have a relatively poor prognosis compared with idiopathic PAH patients, while those with congenital heart disease $\mathrm{PAH}$ have a better survival. The overall survival following transplantation for $\mathrm{PAH}$ has increased to $52-75 \%$ at 5 years and $45-66 \%$ at 10 years [23]. Doublelung, isolated heart, and heart-lung transplantation have been done for PAH, but a double-lung transplant is the most commonly performed modality. Typically, the right heart has a good ability to recover its function after elimination of $\mathrm{PAH}$, but in certain situations, a heart transplant is also necessary [23].

\section{End-of-Life Care}

Prognosis of RVF in the ICU is guarded, and in cases of RVF refractory to aggressive medical management, focus on symptom control and supportive care may be prudent. Ideally, in an oncologic setting the conversation regarding end-of-life care has already been initiated, but often the intensivist may have to focus on the goals of care early during the admission. Frank discussions regarding potential treatment options and prognosis are recommended. Assistance from a dedicated palliative care team may be helpful.

Due to the natural course of PAH and unpredictability of deterioration and adverse outcomes, discussions of prognosis, prospects for transplantation, and the patient's wishes regarding end-of-life care should be held early and readdressed with changes in condition. The multidisciplinary PAH care team most familiar with each patient and family should carry this responsibility in a stable, calm environment. If transplant is not a possibility, then the patient may elect to decline any advanced therapies, including admission to an ICU or resuscitation in case of cardiac arrest.

\section{Prognosis}

Estimates of in-hospital mortality of patients with RVF range from 5\% to $17 \%$ [35]. Evidence for all patients with $\mathrm{PH}$ and RVF is scarce, but there is more data available in the cohort with PAH. The most common cause of death in patients with PAH is RVF, which is also the major determinant of outcomes [14, 87]. In fact, patients with PAH or CTEPH and a pulmonary artery diameter of $>48 \mathrm{~mm}$ have a 7.5-fold increased risk of death [94]. Cardiopulmonary resuscitation for cardiac arrest in PAH was shown in a large retrospective review to be unsuccessful in $79 \%$ of cases, despite $96 \%$ of the arrests taking place in hospitalized patients ( $74 \%$ in ICU setting), with only $6 \%$ surviving more than 90 days neurologically intact. In those who survived, almost all had a rapidly reversible cause for their circulatory arrest [38].

\section{Conclusion}

$\mathrm{PH}$ in the ICU continues to be a challenging and complex clinical issue. Multiple potential etiologies of $\mathrm{PH}$ exist in a cancer center. A keen understanding of the pathophysiology for $\mathrm{PH}$ and consequent RVF is imperative. A high clinical index of suspicion and systematic testing can help identify PH rapidly. Prompt management with continued escalation as needed, along with referral to a specialized center, is helpful. With the advent of new pulmonary vasodilator therapy and increased survival for those with PAH, familiarity with etiology, natural history, and available therapies for PAH is needed. As technologies and targeted therapies emerge, new etiologies and effects on the RV will continue to evolve. 


\section{References}

1. Andreassen AK, Ragnarsson A, Gude E, et al. Balloon pulmonary angioplasty in patients with inoperable chronic thromboembolic pulmonary hypertension. Heart. 2013;99:1415-20.

2. Badesch DB, Raskob GE, Elliott CG, et al. Pulmonary arterial hypertension: baseline characteristics from the REVEAL registry. Chest. 2010;137:376-87.

3. Barber NA, Ganti AK. Pulmonary toxicities from targeted therapies: a review. Target Oncol. 2011;6:235-43.

4. Bartolome SD, Torres F. Severe pulmonary arterial hypertension: stratification of medical therapies, mechanical support, and lung transplantation. Heart Fail Rev. 2016;21:347-56.

5. Bashoura L, Eapen GA, Faiz SA. Pulmonary manifestations of lymphoma and Leukemia. Clin Chest Med. 2017;38:187-200.

6. Bednarczyk J, Strumpher J, Jacobsohn E. Inhaled milrinone for pulmonary hypertension in high-risk cardiac surgery: silver bullet or just part of a broader management strategy? Can J Anaesth. 2016; 63:1122-7.

7. Blom JW, Doggen CJ, Osanto S, et al. Malignancies, prothrombotic mutations, and the risk of venous thrombosis. JAMA. 2005;293(6):715-22.

8. Carlson DL, Willis MS, White DJ, et al. Tumor necrosis factor- $\alpha$-induced caspase activation mediates endotoxin-related cardiac dysfunction. Crit Care Med. 2005;33:1021-8.

9. Chan CM, Klilnger JR. The right ventricle in sepsis. Clin Chest Med. 2008;29(4):661-76. https://doi.org/ 10.1016/j.ccm.2008.07.002.

10. Channick RN, Voswinckel R, Rubin LJ. Inhaled treprostinil: a therapeutic review. Drug Des Devel Ther. 2012;6:19-28. https://doi.org/10.2147/DDDT. S19281.

11. Cherpanath TGV, Lagrand WK, Schultz MJ, Groeneveld ABJ. Cardiopulmonary interactions during mechanical ventilation in critically ill patients. Neth Heart J. 2013;21:166-72.

12. Christenson J, Lavoie A, O'connor M, et al. The incidence and pathogenesis of cardiopulmonary deterioration after abrupt withdrawal of inhaled nitric oxide. Am J Respir Crit Care Med. 2000;161:1443-9.

13. Coz Yataco A, Aguinaga MM, Buck KP, et al. Hospital and intensive care unit management of decompensated pulmonary hypertension and right ventricular failure. Heart Fail Rev. 2016;21(3):323-46.

14. D’Alonzo GE, Barst RJ, Ayres SM, et al. Survival in patients with primary pulmonary hypertension. Results from a national prospective registry. Ann Intern Med. 1991;115:343-9.

15. Dandoy CE, Hirsch R, Chima R, et al. Pulmonary hypertension after hematopoietic stem cell transplantation. Biol Blood Marrow Transplant. 2013; 19:1546-56.
16. Denault AY, Bussières JS, Arellano R, et al. A multicentre randomized-controlled trial of inhaled milrinone in high-risk cardiac surgical patients. Can J Anaesth. 2016;63(10):1140-53. https://doi.org/10.1007/s12630016-0709-8.

17. Denault AY, Haddad F, Jacobsohn E, et al. Perioperative right ventricular dysfunction. Curr Opin Anaesthesiol. 2013;26:71-81.

18. De Wet CJ, Affleck DG, Jacobsohn E, et al. Inhaled prostacyclin is safe, effective, and affordable in patients with pulmonary hypertension, right heart dysfunction, and refractory hypoxemia after cardiothoracic surgery. J Thorac Cardiovasc Surg. 2004; 127:1058-67.

19. Dudzinski DM, Mak GS, Hung JW. Pericardial diseases. Curr Probl Cardiol. 2012;37(3):75-118.

20. Elkayam U, Ng TMH, Hatamizadeh P, et al. Renal vasodilatory action of dopamine in patients with heart failure: magnitude of effect and site of action. Circulation. 2008;117:200-5.

21. Faiz SA, Iliescu C, Lopez-Mattei J, et al. Resolution of myelofibrosis-associated pulmonary arterial hypertension following allogeneic hematopoietic stem cell transplantation. Pulm Circ. 2016;6:611-3.

22. Freitas AF Jr, Bacal F, Oliveira Jde L Jr, et al. Impact of sublingual sildenafil on pulmonary hypertension in patients with heart failure. Arq Bras Cardiol. 2009;92:116-26.

23. Galiè N, Humbert M, Vachiery J-L, et al. 2015 ESC/ERS guidelines for the diagnosis and treatment of pulmonary hypertension: the joint task force for the diagnosis and treatment of pulmonary hypertension of the European Society of Cardiology (ESC) and the European Respiratory Society (ERS): endorsed by: Association for European Paediatric and Congenital Cardiology (AEPC), International Society for Heart and Lung Transplantation (ISHLT). Eur Heart J. 2016;37:67-119.

24. Gildea JJ. Dopamine and angiotensin as renal counterregulatory systems controlling sodium balance. Curr Opin Nephrol Hypertens. 2009; 18:28-32.

25. Greer JR. Pathophysiology of cardiovascular dysfunction in sepsis. BJA Edu. 2015;15:316-21.

26. Greyson CR. Evaluation of right ventricular function. Curr Cardiol Rep. 2011;13:194-202.

27. Greyson CR. Pathophysiology of right ventricular failure. Crit Care Med. 2008;36:S57-65.

28. Grignola JC, Domingo E. Acute right ventricular dysfunction in intensive care unit. Biomed Res Int. 2017; https://doi.org/10.1155/2017/8217105.

29. Grinstein J, Gomberg-Maitland M. Management of pulmonary hypertension and right heart failure in the intensive care unit. Curr Hypertens Rep. 2015;17(5):32. https://doi.org/10.1007/s11906-0150547-z.

30. Guilpain P, Montani D, Damaj G, et al. Pulmonary hypertension associated with myeloproliferative disorders: a retrospective study of ten cases. Respiration. 2008;76:295-302. 
31. Gurghean AL, Savulescu-Fiedler I, Mihailescu A. Multiple cardiac complications after adjuvant therapy for breast cancer: the importance of echocardiography. A case report and review of the literature. Med Ultrason. 2017;19:117-20.

32. Haddad F, Doyle R, Murphy DJ, et al. Right ventricular function in cardiovascular disease, part II: pathophysiology, clinical importance, and Management of Right Ventricular Failure. Circulation. 2008a;117:1717-31.

33. Haddad F, Hunt SA, Rosenthal DN, et al. Right ventricular function in cardiovascular disease, part I: anatomy, physiology, aging, and functional assessment of the right ventricle. Circulation. 2008b;117:1436-48.

34. Haraldsson s A, Kieler-Jensen N, Ricksten SE. The additive pulmonary vasodilatory effects of inhaled prostacyclin and inhaled milrinone in postcardiac surgical patients with pulmonary hypertension. Anesth Analg. 2001;93(6):1439-45.

35. Harjola V-P, Mebazaa A, Čelutkienè J, et al. Contemporary management of acute right ventricular failure: a statement from the heart failure association and the working group on pulmonary circulation and right ventricular function of the European Society of Cardiology. Eur J Heart Fail. 2016;18:226-41.

36. Hickey PM, Thompson AAR, Charalampopoulos A, et al. Bosutinib therapy resulting in severe deterioration of pre-existing pulmonary arterial hypertension. Eur Respir J. 2016;48:1514-6.

37. Hoeper MM, Bogaard HJ, Condliffe R, et al. Definitions and diagnosis of pulmonary hypertension. J Am Coll Cardiol. 2013;62:D42-50.

38. Hoeper MM, Galiè N, Murali S, et al. Outcome after cardiopulmonary resuscitation in patients with pulmonary arterial hypertension. Am J Respir Crit Care Med. 2002;165:341-4.

39. Hossri CAC, Almeida RL, da C, Teixeira FR, et al. Cardiopulmonary exercise testing in pulmonary hypertension. Int J Cardiovas Sci. 2016; https://doi.org/ 10.5935/2359-4802.20160062.

40. Hotchkiss RS, Karl IE. Reevaluation of the role of cellular hypoxia and bioenergetic failure in sepsis. JAMA. 1992;267:1503-10.

41. Hrymak C, Strumpher J, Jacobsohn E. Acute right ventricle failure in the intensive care unit: assessment and management. Can J Cardiol. 2017;33:61-71.

42. Humbert M, Morrell NW, Archer SL, et al. Cellular and molecular pathobiology of pulmonary arterial hypertension. J Am Coll Cardiol. 2004;43:13S-24S.

43. Humbert M, Sitbon O, Chaouat A, et al. Pulmonary arterial hypertension in France. Am J Respir Crit Care Med. 2006;173:1023-30.

44. Iyer AS, Wells JM, Vishin S, et al. CT scan-measured pulmonary artery to aorta ratio and echocardiography for detecting pulmonary hypertension in severe COPD. Chest. 2014;145:824-32.

45. Jentzer JC, Mathier MA. Pulmonary hypertension in the intensive care unit. $\mathrm{J}$ Intensive Care Med. 2016;31:369-85.
46. Kerbaul F, Rondelet B, Motte S, et al. Effects of norepinephrine and dobutamine on pressure load-induced right ventricular failure*. Crit Care Med. 2004;32:1035-40.

47. Kiely DG, Elliot CA, Sabroe I, et al. Pulmonary hypertension: diagnosis and management. BMJ. 2013; https://doi.org/10.1136/bmj.f2028.

48. Kolkailah AA, Hirji S, Piazza G, et al. Surgical pulmonary embolectomy and catheter-directed thrombolysis for treatment of submassive pulmonary embolism. J Card Surg. 2018;33:252-9.

49. Konstam MA, Kiernan MS, Bernstein D, et al. Evaluation and Management of Right-Sided Heart Failure: a scientific statement from the American Heart Association. Circulation. 2018;137:e578-622.

50. Krishnan U, Mark TM, Niesvizky R, et al. Pulmonary hypertension complicating multiple myeloma. Pulm Circ. 2015;5:590-7.

51. Lang IM. Management of acute and chronic RV dysfunction. Eur Heart J Suppl. 2007;9:H61-7.

52. Ling Y, Johnson MK, Kiely DG, et al. Changing demographics, epidemiology, and survival of incident pulmonary arterial hypertension: results from the pulmonary hypertension registry of the United Kingdom and Ireland. Am J Respir Crit Care Med. 2012;186:790-6.

53. Lund LH, Edwards LB, Kucheryavaya AY, et al. The registry of the International Society for Heart and Lung Transplantation: thirty-second official adult heart transplantation report-2015; focus theme: early graft failure. J Heart Lung Transplant. 2015;34:1244-54.

54. Machado RF, Farber HW. Pulmonary hypertension associated with chronic Hemolytic Anemia and other blood disorders. Clin Chest Med. 2013;34:739-52.

55. Machuca TN, de Perrot M. Mechanical support for the failing right ventricle in patients with precapillary pulmonary hypertension. Circulation. 2015;132:526-36.

56. Mangi MA, Rehman H, Bansal V, et al. Ultrasound assisted catheter-directed thrombolysis of acute pulmonary embolism: a review of current literature. Cureus. 2017; https://doi.org/10.7759/cureus.

57. McConnell MV, Solomon SD, Rayan ME, et al. Regional right ventricular dysfunction detected by echocardiography in acute pulmonary embolism. Am J Cardiol. 1996;78:469-73.

58. McGoon MD, Benza RL, Escribano-Subias P, et al. Pulmonary arterial hypertension: epidemiology and registries. J Am Coll Cardiol. 2013;62:D51-9.

59. McGoon MD, Krichman A, Farber HW, et al. Design of the REVEAL registry for US patients with pulmonary arterial hypertension. Mayo Clin Proc. 2008;83:923-31.

60. McLaughlin VV, Shah SJ, Souza R, et al. Management of pulmonary arterial hypertension. J Am Coll Cardiol. 2015;65:1976-97.

61. Mekontso Dessap A, Boissier F, Charron C, et al. Acute cor pulmonale during protective ventilation for acute respiratory distress syndrome: prevalence, 
predictors, and clinical impact. Intensive Care Med. 2016;42:862-70.

62. Montani D, Bergot E, Günther S, et al. Pulmonary arterial hypertension in patients treated by dasatinib. Circulation. 2012;125:2128-37.

63. Montani D, Lau EM, Dorfmüller P, et al. Pulmonary veno-occlusive disease. Eur Respir J. 2016; 47:1518-34.

64. Naeije R, Manes A. The right ventricle in pulmonary arterial hypertension. Eur Respir Rev. 2014;23:476-87.

65. Oudiz RJ. Pulmonary hypertension associated with left-sided heart disease. Clin Chest Med. 2007;28:233-41.

66. Peacock AJ, Murphy NF, McMurray JJV, et al. An epidemiological study of pulmonary arterial hypertension. Eur Respir J. 2007;30:104-9.

67. Pengo V, Lensing AWA, Prins MH, et al. Incidence of chronic thromboembolic pulmonary hypertension after pulmonary embolism. N Engl J Med. 2004; 350:2257-64.

68. Price LC, Dimopoulos K, Marino P, et al. The CRASH report: emergency management dilemmas facing acute physicians in patients with pulmonary arterial hypertension. Thorax. 2017;72:1035-45.

69. Qiu J, Jia L, Hao Y, et al. Efficacy and safety of levosimendan in patients with acute right heart failure: a meta-analysis. Life Sci. 2017;184:30-6.

70. Ranchoux B, Günther S, Quarck R, et al. Chemotherapy-induced pulmonary hypertension: role of alkylating agents. Am J Pathol. 2015;185:356-71.

71. Rashdan S, Minna JD, Gerber DE. Diagnosis and management of pulmonary toxicity associated with cancer immunotherapy. Lancet Respir Med. 2018;6:472-8.

72. Rhodes A, Evans LE, Alhazzani W, et al. Surviving sepsis campaign: international guidelines for Management of Sepsis and Septic Shock: 2016. Crit Care Med. 2017;45:486-552.

73. Riou M, Seferian A, Savale L, et al. Deterioration of pulmonary hypertension and pleural effusion with bosutinib following dasatinib lung toxicity. Eur Respir J. 2016;48:1517-9.

74. Roberts KE, Hamele-Bena D, Saqi A, et al. Pulmonary tumor embolism: a review of the literature. Am J Med. 2003;115:228-32.

75. Sahay S, Tonelli AR. Pericardial effusion in pulmonary arterial hypertension. Pulm Circ. 2013;3:467-77.

76. Salsano A, Sportelli E, Olivieri GM, et al. RVAD support in the setting of submassive pulmonary embolism. J Extra Corpor Technol. 2017;49:304-6.

77. Sandoval J, Gaspar J, Pulido T, et al. Graded balloon dilation atrial septostomy in severe primary pulmonary hypertension. J Am Coll Cardiol. 1998;32:297-304.

78. Seegobin K, Babbar A, Ferreira J, et al. A case of worsening pulmonary arterial hypertension and pleural effusions by bosutinib after prior treatment with dasatinib. Pulm Circ. 2017;7:808-12.
79. Shaikh AY, Shih JA. Chemotherapy-induced cardiotoxicity. Curr Heart Fail Rep. 2012;9:117-27.

80. Simonneau G, Gatzoulis MA, Adatia I, et al. Updated clinical classification of pulmonary hypertension. J Am Coll Cardiol. 2013;62:D34-41.

81. Steppan J, Diaz-Rodriguez N, Barodka VM, et al. Focused review of perioperative Care of Patients with pulmonary hypertension and proposal of a perioperative pathway. Cureus. 2018; https://doi.org/10.7759/ cureus. 2072.

82. Strumpher J, Jacobsohn E. Pulmonary hypertension and right ventricular dysfunction: physiology and perioperative management. J Cardiothorac Vasc Anesth. 2011;25:687-704.

83. Sztrymf B, Souza R, Bertoletti L, et al. Prognostic factors of acute heart failure in patients with pulmonary arterial hypertension. Eur Respir J. 2010;35:1286-93.

84. Tamura Y, Kimura M, Takei M, et al. Oral vasopressin receptor antagonist tolvaptan in right heart failure due to pulmonary hypertension. Eur Respir J. 2015; 46:283-6.

85. Trow TK, Christina Argento A, Rubinowitz AN, et al. A 71-year-old woman with myelofibrosis, hypoxemia, and pulmonary hypertension. Chest. 2010;138:1506-10.

86. Ventetuolo CE, Klinger JR. Management of acute right ventricular failure in the intensive care unit. Ann Am Thorac Soc. 2014;11:811-22.

87. Vonk Noordegraaf A, Galie N. The role of the right ventricle in pulmonary arterial hypertension. Eur Respir Rev. 2011;20:243-53.

88. Weinberg A, Tapson VF, Ramzy D. Massive pulmonary embolism: extracorporeal membrane oxygenation and surgical pulmonary embolectomy. Semin Respir Crit Care Med. 2017;38:66-72.

89. Weinberger B, Laskin DL, Heck DE, et al. The toxicology of inhaled nitric oxide. Toxicol Sci. 2001;59:5-16.

90. Weitsman T, Weisz G, Farkash R, et al. Pulmonary hypertension with left heart disease: prevalence, temporal shifts in Etiologies and outcome. Am J Med. 2017;130:1272-9.

91. Westerhof BE, Saouti N, van der Laarse WJ, et al. Treatment strategies for the right heart in pulmonary hypertension. Cardiovasc Res. 2017;113:1465-73.

92. Yusuf SW, Venkatesulu BP, Mahadevan LS, et al. Radiation-induced cardiovascular disease: a clinical perspective. Front Cardiovasc Med. 2017;4:66. https://doi.org/10.3389/fcvm.2017.00066.

93. Zamanian RT, Haddad F, Doyle RL, et al. Management strategies for patients with pulmonary hypertension in the intensive care unit. Crit Care Med. 2007;35: 2037-50.

94. Żyłkowska J, Kurzyna M, Florczyk M, et al. Pulmonary artery dilatation correlates with the risk of unexpected death in chronic arterial or thromboembolic pulmonary hypertension. Chest. 2012;142:1406-16. 